\title{
Referencias hispanas en obras de Shostakovich de la década de los años 50
}

\section{Hispanic References in Shostakovich's Works of the 50's}

\author{
Ana María Mula Pérez \\ Orquesta y Coro de la Comunidad de Madrid \\ anamariamulaperez@gmail.com
}

\section{RESUMEN}

A pesar del interés biográfico y compositivo del autor soviético Dmitri Shostakovich, el presente artículo se centrará exclusivamente en algunas de las obras del compositor que presentan ciertas referencias hispanas. A lo largo de toda su carrera Shostakovich incluyó en varias de sus creaciones elementos musicales que podrían vincularse con la sonoridad prototípica de España. Sin embargo, en este trabajo llevaremos a cabo una investigación sobre aquéllas pertenecientes a la década de los años cincuenta, muy relevantes desde el prisma político por coincidir con el fallecimiento de Joseph Stalin.

Palabras clave: Shostakovich, España, música, folclore, 1950.

\begin{abstract}
Despite the biographical and compositional interest of the soviet author Dmitri Shostakovich, this article will be focus on some of the composer's works that present some Hispanic references. Throughout his career Shostakovich included, in several of his creations, musical elements which can be related to the prototypical sonority of Spain. However, this investigation will focus on those works belonging to the decade of the fifties, very relevant from the political prism to coincide with the death of Stalin.
\end{abstract}

Key words: Shostakovich, Spain, music, folklore, 1950.

Mula Pérez, A. M. (2017). Referencias hispanas en obras de Shostakovich de la década de los años 50. Cuadernos de Investigación Musical, 3, 20-49. 


\section{REFERENCIAS HISPANAS EN OBRAS DE SHOSTAKOVICH DE LA DÉCADA DE LOS AÑOS 50}

\section{INTRODUCCIÓN}

La música española ha servido como fuente de inspiración muy recurrida por muchos compositores europeos a lo largo de la historia de la música (Zamudio, 2001: 136). En sus composiciones, los autores quisieron reflejar la cultura musical hispana a través de melodías escuchadas en sus viajes por España o como reflejo de su imaginación y del ideario exótico que dicho país les inspiraba.

Podría decirse que el interés por lo lejano ha estado presente a lo largo de la mayor parte de la historia de la música. Alrededor de los años 1500 ya se aprecia esta tendencia compositiva en algunas óperas basadas en la antigua Grecia o en las Cruzadas, así como oratorios y otras obras religiosas ambientadas en la Tierra Santa (Oriente Medio). Algunos ejemplos de ellas podrían ser: Armide (1686) de Jean-Batiste Lluly (1632-1687); Rinaldo (1711), Giulio Cesare in Egitto (1724) y Serse (1738) de George Fiedrich Haendel (1685-1759); La rencontre imprévue, on Les pèlerins de la Mecque (1763) de Cristoph Willibald Gluck (17141787); La Pasión según San Juan (1724) de Johan Sebastian Bach (1685-1750) o El rapto en el serrallo (1782) de Wolfgang Amadeus Mozart (1756-1791) (Locke, 2015: 3-40).

A partir del s. XIX este gusto por lo exótico empezó a fundamentarse en la pluralidad de los lenguajes, rompiendo así con la idea de la existencia de un único eje de desarrollo, el del alemán-vienés: los conciertos, las sinfonías, las sonatas, el melodrama, el lenguaje melódico y tonal los conciertos, las sinfonías, las sonatas, el lenguaje melódico y tonal. Esta nueva corriente de inspiración, influenciada en gran parte por la literatura, originó la necesidad de viajar a otros lugares con el fin de descubrir nuevas culturas, siendo España uno de los ideales en la perspectiva exótica de aquel momento.

Gracias a esta ruptura con el convencionalismo compositivo tradicional, hoy en día encontramos numerosas composiciones coloristas con elementos y temas propios del folclore español, como es el caso de la Jota aragonesa y el Recuerdo de una noche en Madrid de Mijaíl Glinka (1804-1857), el Capricho español de Rimsky-Korsakov (1844-1908), la Rapsodia española de Maurice Ravel (1875-1937), la Jota de Emmanuel Chabrier (1841-1894) o la ópera Carmen de Georges Bizet (1838-1875) por nombrar algunas de las más conocidas. Salvo Carmen, el resto son obras orquestales, algo que a pesar de no ser un aspecto típico español permitió a los compositores plasmar su propia percepción de la sonoridad musical española. Es decir, en las obras basadas en el folclore hispano creadas por autores europeos no se perseguía necesariamente la idea de identidad, a pesar de que muchos compositores propiamente hispanistas consideraron que todas estas creaciones mostraban perfectamente la esencia de lo que era España, como es el caso de Manuel de Falla.

La presencia de reminiscencias sonoras españolas insertas en composiciones musicales de autores rusos se remonta a décadas previas a la figura de Dmitri Shostakovich (1906-1975), por lo que no resulta algo novedoso. Especialmente en torno al Nacionalismo musical se produjo una eclosión de obras musicales rusas vinculadas con la sonoridad estereotípica hispana. Poco antes mencionábamos a Glinka y a Korsakov, compositores bastante anteriores a Shostakovich y que no vivieron dentro del contexto del Partido de Stalin (1878-1953). Pero ¿Qué hay de aquéllos que también vivieron la represión del socialismo ruso? ¿Pudieron ellos plasmar esos ideales exóticos españoles? y si es así, ¿Cómo pudieron entrar en contacto con la cultura musical española? 


\section{ANA María Mula Pérez}

Como compositores de referencia contemporáneos a Shostakovich y que presentan reminiscencias sonoras hispanas en algunas de sus obras, podríamos hacer mención a Ígor Stravinsky (1882-1971) ("Española" de Cinco piezas fáciles) y a Serguéi Prokófiev (1891-1953) (Sinfonía núm. 2, op. 40, Sinfonía núm. 3, op. 44 y Concierto núm. 2 para violín, op. 63). La gran diferencia entre estos dos autores y el protagonista de este artículo se encuentra en que los dos primeros tuvieron un contacto directo con la cultura española. A raíz de la Revolución de 1927 Stravinsky abandonó definitivamente la URSS y durante toda su vida pudo viajar por todo el mundo, siendo uno de sus destinos España con motivo de la interpretación de dos de sus ballets más famosos, Petrushkea y El pájaro de fuego (Hess, 2004: 106). Por su parte, Prokófiev también abandonó el país tras la Revolución, aunque a diferencia de Stravinsky regresó a la URSS en 1936, donde permaneció hasta su muerte. Sin embargo, durante los dieciocho años que estuvo exiliado pudo mantener un contacto muy directo con España, gracias tanto a su matrimonio con una muchacha española (Chemberdjí, 2010: 1), como a la estrecha relación de amistad que mantuvo con Manuel de Falla (Franco, 1977: s.p) y a su viaje a España con motivo del estreno en Madrid de su Concierto para violín núm. 2, op. 63.

Por lo tanto, cada uno con sus circunstancias, tanto Prokófiev como Stravinsky pudieron establecer una relación directa con la cultura española. Sin embargo, por lo que respecta a Shostakovich nos planteamos la siguiente cuestión: teniendo en cuenta que, por lo que sabemos, Shostakovich nunca viajó a España, a lo que debemos añadir las represiones implantadas por el Partido y la carencia de materiales y de fuentes a las que recurrir, ¿Cómo pudo éste tomar contacto con la cultura musical hispana? Muchos autores defienden que pudo ser posible a través de los emigrantes españoles, ya que con el comienzo de la Guerra Civil (1936) la Unión Soviética fue la única potencia que se decantó por apoyar al bando republicano enviando al país gran cantidad de material de guerra, agentes y asesores militares (Kowalsky, 2004: 1-4).

A pesar de la gran dificultad que pudo tener Shostakovich a la hora de tomar contacto con la cultura musical española, podemos encontrar dentro de su legado compositivo varias obras que presentan referencias hispanas de algún tipo. En orden cronológico, serían:

- Saludos a España, op. 44 (1936). Música incidental con referencias tanto temáticas como sonoras.

- Sinfonía núm. 5, op. 47 (1936). Con material melódico inspirado en el tema de la "Habanera" de la ópera Carmen (1875) de Bizet, inspirada a su vez en la canción española "El Arreglito" (1840) de Sebastián Iradier (1809-1865).

- La “Tarantella” de la Suite Gadfly, op. 97 (1955). Repleta de elementos sonoros y materiales melódicos típicos del folclore español.

- Canciones españolas para mezzosoprano y piano, op. 100 (1956). Además de la referencia directa que encontramos en el título, constituye un conjunto de canciones en las que se encuentran gran cantidad de elementos compositivos típicos del folclore español, dotando así a la obra entera de ese aire sonoro tan característico de la música española.

- El "Vals núm. 2" de la Suite para orquesta de variedades (1956). Presenta material melódico procedente del estribillo de una canción tradicional española. 


\section{REFERENCIAS HISPANAS EN OBRAS DE SHOSTAKOVICH DE LA DÉCADA DE LOS AÑOS 50}

- Sinfonía núm. 14, op. 135 (1969). Incluye dos movimientos inspirados en poemas de Federico García Lorca, donde emplea tanto elementos compositivos como instrumentos típicos del folclore español.

Por lo tanto y a pesar de que las dificultades planteadas anteriormente puedan generar controversia, existen obras de Shostakovich en las cuales podemos encontrar referencias de origen hispano. Aunque todas ellas resultan de gran interés, en este artículo nos centraremos en aquellas pertenecientes a la década de los años 50.

\section{REFERENCIAS HISPANAS EN OBRAS DE SHOSTAKOVICH DE LOS AÑOS $\mathbf{5 0}$}

De forma generalizada podría decirse que las composiciones de Shostakovich pertenecientes a este periodo no han tenido mayor relevancia ni tampoco están al nivel de muchas de las anteriores, a excepción de la Sinfonía núm. 10, op. 93 (1953). La década de los 50 supuso más bien el resurgir de muchas de las obras que no pudieron ver la luz anteriormente debido a la gran represión que existió durante los años de Stalin, como, por ejemplo, el Concierto para violín núm. 1, op. 77 (1948), (Meyer, 1997: 301). Sin embargo, teniendo en cuenta el fin investigativo de este artículo son varias las obras de esta época que sí resultan muy interesantes debido a que presentan reminiscencias hispanas. Concretamente son tres: la "Tarantella" de la banda sonora de la película El Tábano; las Canciones españolas para mezzo soprano y el "Vals núm. 2" de la Suite para orquesta de variedades. En ellas los elementos hispanos que principalmente se observan son de tipo sonoro, tanto porque nos recuerdan a alguna canción de origen español como por los recursos compositivos empleados por Shostakovich, dando lugar a ese aire tan característico del folclore español. Asimismo, a pesar de que las referencias sonoras sean las predominantes también encontraremos alguna de tipo temático, como es el caso de "Adiós Granada", la primera de las seis Canciones Españolas.

A fin de poder evidenciar y clarificar las referencias hispanas se realizará un pequeño análisis de cada una de ellas.

\subsection{SUITE GADFLY, OP. 97 (1955)}

The Gadflay (El Tábano) es el nombre que recibe la película soviética basada en la novela homónima de Ethel Lilian Voynich (1864-1960) (Li, 2016: 33). La historia se desarrolla en la Italia dominada por los austriacos durante los años 30 y 40 del siglo XIX. Se trata de un melodrama entremezclado con aventuras y una historia de amor, donde el papel de El Tábano corresponde a un revolucionario independentista que finalmente es capturado y convertido en mártir del movimiento de la liberación italiana una vez fusilado (Riley, 2004: 80).

Shostakovich fue el elegido para poner música a este largometraje en 1955 y compuso una banda sonora de la cual surgió posteriormente la Suite Gadfly. A pesar de que, 


\section{ANa María Mula Pérez}

en un principio, escribió muchísima música, finalmente muchas de las partes fueron cortadas, dando lugar a una banda sonora orquestal ${ }^{1}$ formada por veinticuatro números ${ }^{2}$ :

1. Overtura (Obertura): Moderato con moto.

2. The Cliff (El Acantilado): Moderato.

3. Youth (Juventud): Allegretto - Moderato.

5. Confession (Confesión), (solo órgano): Andante.

7. Box on the ear (Caja en la oreja): Andante con moto.

8. Laughter (Risa): Andante - Adagio.

9. Barrel organ (Organillo): Allegretto.

10. Divine service at the Cathedral (Servicio divino en la Catedral), (solo órgano): Andante.

12. Exit from the Cathedral (Salir de la Catedral): Moderato.

13. Contredanse (Cuadrilla): Moderato.

14. Galop (Galope): Presto.

15. Guitars (Guitarras): Andantino.

16. At the market place (En el Mercado): Andantino.

17. The rout (La Derrota): Adagio.

18. The Passage of Montaneli (El Paso de Montaneli): Moderato.

19. Finale (Final): Moderato con moto.

20. The Austrians (Los Austriacos): Allegro non toppo.

22. The river (El Río): Allegro.

23. Gema's room (La habitación de Gema): Moderato con moto. (Hulme, 2010: 383-384).

Más tarde, con la autorización de Shostakovich, su amigo Lev Atovmyan elaboró la Suite Gadfly. A partir tanto de la música original del compositor (incluyendo la que no fue utilizada en la banda sonora) como de los 24 números de la película realizó una reestructuración y una reorquestación de todo, dando lugar a una suite sinfónica en 12 secciones:

1. Overture (Obertura): Moderato con moto. $\left(1^{3}\right)$.

2. Contredance (Cuadrilla): Moderato. (13).

\footnotetext{
${ }^{1}$ La Suite consta de la siguiente instrumentación: cuerdas, piccolo, dos flautas, dos oboes, tres clarinetes (en La y Si b), dos fagotes, cuatro trompas, tres trompetas, tres trombones, una tuba, abundante percusión, arpa, órgano y dos guitarras.

${ }^{2}$ No se incluyen los números 4, 6, 11, 21 y 24 ya que no aportan ningún tema melódico nuevo.

${ }^{3}$ Las cifras indican los números de la banda sonora de los que proviene cada movimiento.
}

Cuadernos de Investigación Musical, 2017, diciembre, $\mathrm{n}^{\circ}$ 3, págs. 20-49. 


\section{REFERENCIAS HISPANAS EN OBRAS DE SHOSTAKOVICH DE LA DÉCADA DE LOS AÑOS 50}

3. People's Holiday (Las Vacaciones de la gente), también nombrada como: Folk Fest, Folk Festival, Tarantella, Neopolitane Dance o Spanish Dance: Allegro Vivace. (16).

4. $\quad$ Interlude (Interludio): Adagio. (17).

5. $\quad$ Barren Organ Waltz (Vals del organillo): Allegretto. (9).

6. Galop (Galope): Allegro. (14).

7. Prelude (Preludio) -"Introduction" en la partitura de 1960-: Andantino. (15 y 5).

8. $\quad$ Romance (Romanza): Allegro moderato. (3 y 7 ).

9. Intermezzo (Intermedio): Andante. (10, 12 y 18).

10. Nocturne (Nocturno): Moderato. (23).

11. Scene (Escena): Moderato. (2).

12. Finale (Final): Allegro non troppo. (20). (Hulme, 2010: 384).

Atovmyan llevó a cabo esta compilación el mismo año en que Shostakovich escribió la banda sonora (1955). Sin embargo, no fue publicada hasta 1960 así como la primera grabación se realizó un año después (1961) (Riley, 2004: 80-82). Uno de los cambios más notables de Atovmyan es la orquestación de la música original escrita para órgano, facilitando así la posibilidad tanto de interpretar la suite en conciertos como de realizar grabaciones de la misma.

De los 12 números anteriores podríamos decir que la "Romanza" es el gran hit de esta suite. Sin embargo, por el tema en cuestión a tratar en este artículo el movimiento que nos resulta de mayor interés es el número 3. Como podemos observar en el listado anterior, algunas transcripciones se refieren a este movimiento como "Tarantella", "Fiesta popular", "Danza napolitana" o "Danza española". Teniendo en cuenta la ambientación de la película, podríamos asociar este número de la suite como vínculo con Italia. Sin embargo, tenemos dos razones por las que defender que, más bien, está vinculada con España.

La primera es que debemos puntualizar que la tarantella napolitana suele estar escrita en compás de 6/8, mientras que Shostakovich escribe esta danza en compás de 4/4. La segunda razón tiene que ver con la identificación de reminiscencias del folclore español en ella. El primer elemento que nos llama la atención es el trabajo del adorno en el tema principal, es decir, el empleo de melismas o melodías con gran desarrollo virtuosístico, muy presente en la música española. Asimismo, dentro de este virtuosismo se aprecia un floreo típico del folclore español y no del bel canto italiano. De hecho, hemos identificado que Ravel utiliza este mismo material temático en su famoso bolero tan vinculado a España. 

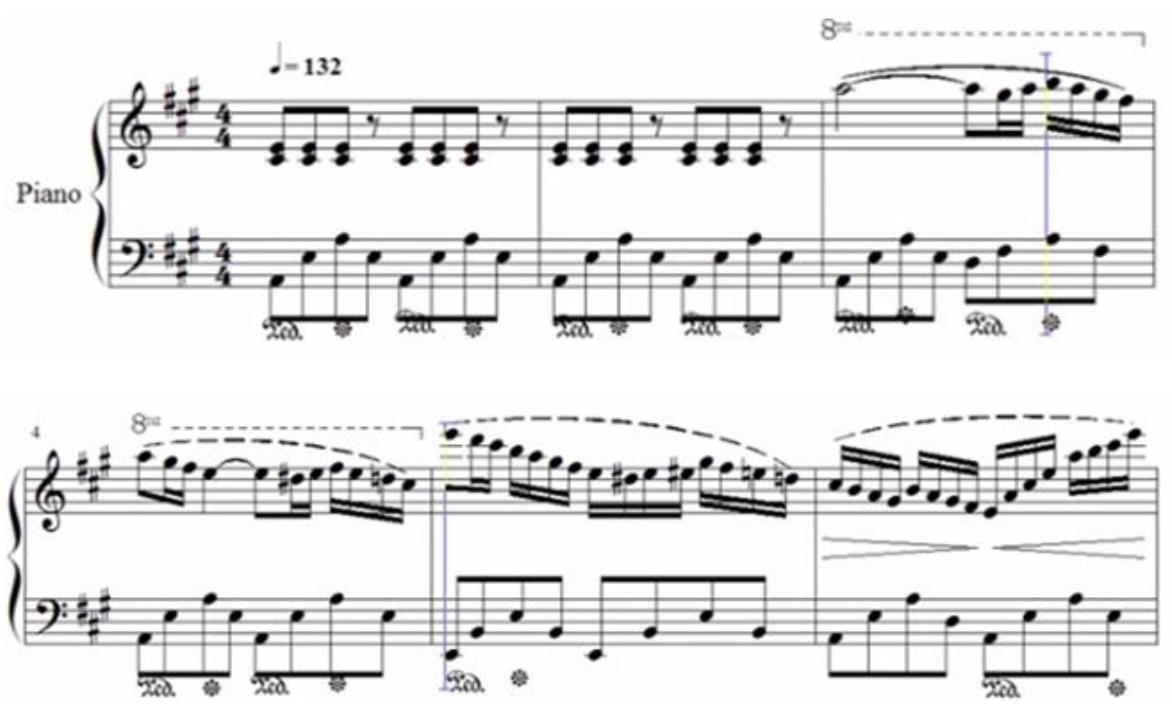

Fig. 1. Danza española, Shostakovich.
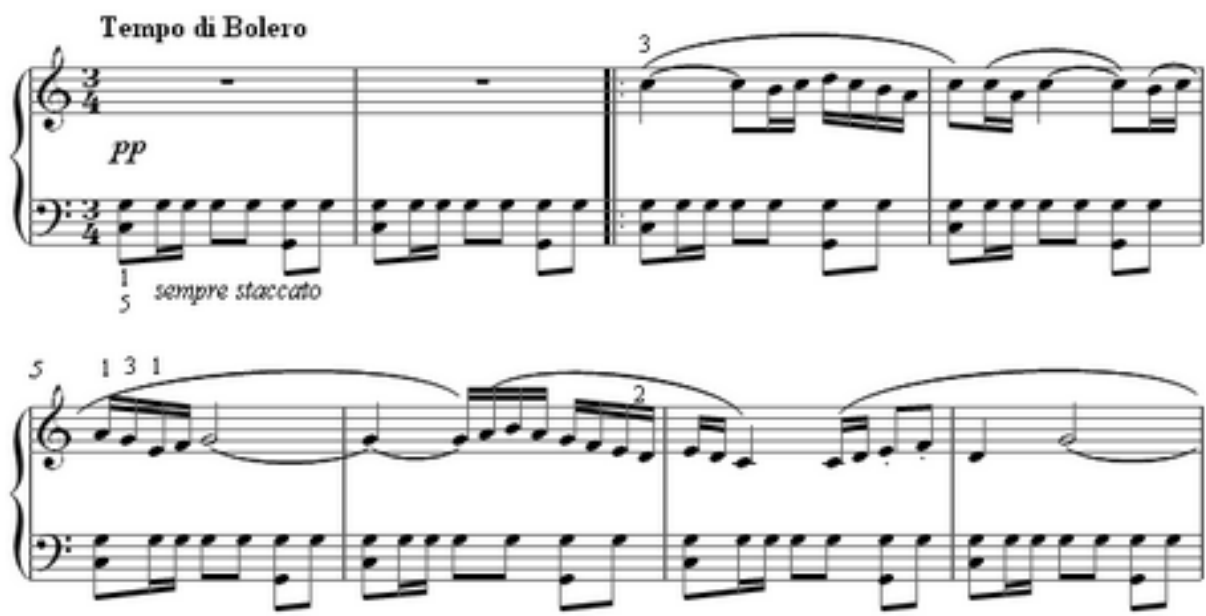

Fig. 2. Bolero, Ravel.

La influencia de la música española en el legado compositivo de Ravel es evidente pues, además de contar con antecedentes familiares vinculados a España (Carpentier, 1987: p. 305), incluyó reminiscencias del folclore español en muchas de sus obras como el mencionado Bolero, la Rapsodia Española y Hora española. Por tanto, la semejanza de material temático entre el número 3 de la Suite Gadfly de Shostakovich y el Bolero de Ravel podría confirmar nuestra visión hispana del legado del músico soviético. 


\section{REFERENCIAS HISPANAS EN OBRAS DE SHOSTAKOVICH DE LA DÉCADA DE LOS AÑOS 50}

\subsection{CANCIONES ESPAÑOLAS, PARA MEZZOSOPRANO Y PIANO, OP. 100 (1956).}

A pesar de que no es una de las obras más interpretadas en los programas de concierto del panorama actual, las Canciones españolas (simplemente el título ya hace una alusión directa) son un claro ejemplo de la existencia de referencias hispanas dentro de la obra compositiva de Shostakovich. Se trata de una obra compuesta por seis canciones: "AAdiós, Granada!”, "Pequeñas estrellas”, "El primer encuentro”, "Ronda”, "La muchacha de los ojos negros" y "Sueño". Shostakovich entró en contacto con esta música gracias a un cantante amigo suyo y compuso esta obra sobre melodías y textos populares españoles (Fay, 2005: 366) que, al parecer, estaban inspirados en las canciones que cantaban los niños emigrados a la Unión Soviética durante la Guerra Civil ${ }^{4}$. En cuanto a los textos, fueron sacados de un volumen de poemas españoles y traducidos al ruso por Sergey Bolotin y Tatiana Sikorskaya (Fay, 2005: 357).

Con la intención de obtener un mayor conocimiento sobre estas referencias tan significativas hemos realizado una profunda investigación para poder establecer una conexión directa entre cada una de las canciones de Shostakovich y canciones populares españolas. A pesar de ello y debido al anonimato de las canciones originales, solamente hemos podido localizar el origen de una ellas (Heyer, 2014: 169).

\section{1. “¡Adiós, Granada!”}

Traducción: S. Bolotin.

Título original: Adiós Granada.

La investigación que hemos realizado nos lleva a pensar que esta pieza procede de la canción "Granadinas" o "Adiós, Granada", perteneciente a la zarzuela Los Emigrantes, cuadro lírico de un sólo acto con texto de Pablo Cases y música de Tomás Barrera y Rafael Calleja. A pesar de que la letra de la canción no corresponde del todo con la traducción realizada por Bolotin, hay varias razones por las que podemos afirmar que procede de las "Granadinas". La primera es el indiscutible parecido musical. A pesar de que la tonalidad empleada por Shostakovich es diferente, así como el acompañamiento, la parte vocal, musicalmente hablando, presenta una perfecta coincidencia en ambas canciones. Es más, teniendo en cuenta que conocemos la canción de la que proviene, podríamos decir en este caso que Shostakovich simplemente la re-armonizó dándole ese toque sonoro tan personal suyo. Por otra parte, tras el estreno de la zarzuela en 1905, “Adiós, Granada" es lo único que ha quedado de esta obra escénica de forma popularizada, e incluso, en la mayoría de los casos ni siquiera se la vincula con la obra a la que pertenece; por lo que puede ser perfectamente posible que en su momento ya fuera popular y llegara a oídos de Shostakovich a través de la emigración española.

\footnotetext{
${ }^{4}$ Disponible en: < $\underline{\text { http://espina-roja.blogspot.com.es/2012/02/canciones-espanolas-del-compositor.html }>}$ [Última visita: 15 de marzo de 2018].
} 


\section{ANa María Mula Pérez}

Otro de los aspectos considerados es la temática. La zarzuela muestra una gran sensibilidad hacia el problema social de la emigración que sufrió España entre 1900 y 1930. Muchos españoles tuvieron que abandonar el país en busca de una vida mejor debido a factores económicos, políticos y demográficos. Si Shostakovich pretendía escribir un ciclo de canciones españolas y él mismo vivió el problema de la emigración durante la Guerra Civil, era una temática muy oportuna. Del mismo modo, puede que se sintiera sensibilizado con este asunto ya que él también sufrió un régimen dictatorial y represivo por el que muchísima gente tuvo que abandonar su hogar.

En cuanto a la falta de coincidencia entre la letra de la canción original y el texto traducido por Bolotin, no debería ser considerado como un factor determinante para desvincular la procedencia. En primer lugar, porque tal y como comentábamos al principio, al parecer Shostakovich llegó a esta música gracias a la música tradicional que cantaban los niños exiliados, pero los textos fueron sacados de un volumen de poemas españoles, por lo que podría ser factible que lo único que quedara como tal de esas canciones fuera la música y que Shostakovich añadiera otro texto en ellas. Por otra parte, la traducción del texto a otro idioma siempre está determinada por la música, siendo común que haya modificaciones a fin de hacer coincidir los acentos, el ritmo y las rimas. Asimismo, no hay que olvidar que se ha convertido en música popular y que la vía por la que le pudo llegar al compositor fue a través de los cantos de los españoles que emigraron de España, el coloquial «boca a boca», uno de los mejores medios para perdurar y popularizar pero por el que también la música es más susceptible al cambio tanto a nivel musical como a nivel del texto.

A continuación, se incluyen los textos de las dos canciones con la intención de mostrar las diferencias:

\begin{tabular}{|c|c|}
\hline iAdiós, Granada! & Adiós Granada (Los emigrantes) \\
¡Adiós, Granada, Granada mía! & \\
Tengo que dejarte, & Adiós, Granada, Granada mía, \\
no volveré nunca jamás. & Adiós, Granada, Granada mía, \\
Adiós, mi tierra, amada, & Ya no volveré a verte más en la vía, \\
goce de mis ojos. & ¡Ay, me da pena, \\
¡Para siempre, adiós! ¡Ay! & vivir lejos de tu vega \\
Tu recuerdo será mi única alegría, & y del sitio donde reposa \\
mi tierra amada, mi tierra natal. & el cuerpo de mi morena! \\
Para siempre, la pena ha atravesado mi corazón, \\
he perdido todo lo que amaba en la vida. \\
Mi amor descansa en la oscuridad de la tumba, \\
la vida ha partido. & Dobla, campana, campana, dobla, \\
Todo lo que me rodea se ha vuelto odioso. & Dobla, campana, campana, dobla, \\
No tengo la fuerza de vivir como antes, & Que tu triste sonido comentan las olas. \\
allí donde la juventud era tan luminosa. & iQué horas tan negras! \\
& En la cajita la veo \\
& y en la mié de sus labios
\end{tabular}




\section{REFERENCIAS HISPANAS EN OBRAS DE SHOSTAKOVICH DE LA DÉCADA DE LOS AÑOS 50}

Como comentábamos, no hemos podido localizar tan a ciencia cierta las melodías españolas que dieron origen al resto de las canciones de Shostakovich. A pesar de ello, debido a que encontramos en todas reminiscencias sonoras que recuerdan al folclore español, hemos querido localizar los recursos que contienen y, de ese modo, justificar su procedencia. Para ello, gracias a expertos como directores de orquesta y músicos con gran experiencia en música española, hemos realizado una recopilación tanto de las características generales que determinan el folclore como de aquéllas referentes a elementos propios de la música tradicional hispana.

Independientemente del país de origen, existen algunos aspectos generales que determinan la música folclórica. Como ya sabemos es música popular o del pueblo, por lo que suelen predominar melismas o melodías sencillas en las que priman los grados conjuntos con pocos saltos. El empleo de la repetición también es un recurso muy presente, siendo muy frecuentes los ostinatos tanto rítmicos como armónicos, sobre todo en los acompañamientos. A pesar de que suele predominar el empleo de una única tonalidad para la misma canción, en muchos casos aparece el juego del uso del relativo mayor o menor como contraste entre algunas de las partes, presentando por lo general una estructura clásica y sencilla como puede ser A B A. Por otro lado, el modo en el que se finaliza la composición también puede darnos algunas pistas debido a que muchos temas populares acaban acentuando el pulso débil del compás. Por último, cabe destacar el uso de los modos, ya que es habitual encontrar melodías escritas de forma modal y el acompañamiento de manera tonal o viceversa, siendo el modo frigio uno de los modos más representativos del folclore español.

Teniendo en cuenta algunas de las características que presenta la música folclórica de forma generalizada observamos que todas las mencionadas anteriormente o gran parte de ellas están presentes en las seis canciones de Shostakovich. Veamos ahora cuáles son los recursos específicos y necesarios que emplea para conseguir esa sonoridad española. Para ello y a fin de que quede reflejado de la mejor manera posible, se mostrarán ejemplos sobre la partitura de algunos de los momentos donde se encuentran estos elementos, diferenciando los generales del folclore en color azul y los característicos del español en rojo, así como algunas anotaciones en verde.

\section{2. "Pequeñas estrellas".}

Traducción: T. Sikorskaya.

Título original: "Mozuka".

Se trata de una canción escrita en la tonalidad de $L a b M$ (tema A) y Fa $M$ (tema B) en compás de $6 / 8$ de poco más de un minuto de duración y con la siguiente estructura: introducción, tema A, tema B y coda. A través del título original en español, "Mozuka", hemos encontrado la existencia de dos canciones de origen español con el mismo nombre. Ambas pertenecen al compositor cántabro Arturo Duo Vital (1901-1964) quien escribió 


\section{ANa María Mula Pérez}

numerosas piezas corales, además de música tradicional española como boleros, seguidillas, etc.

La primera de ellas, Mozuca (Montañesa) (1951), corresponde a una canción para coro mixto escrita en compás de 6/8. Realmente, las similitudes que encontramos con la canción de Shostakovich son poco relevantes ya que se reducen al nombre y al compás y es por ello que no la consideraremos como posible canción de la que provenga "Pequeñas estrellas".

La segunda es la Suite Montañesa (1949). Se trata de una obra instrumental formada por tres movimientos, de los cuáles el tercero tiene el nombre de "Mozuca, da bien la vuelta". Lo primero que nos llama la atención es el gran parecido que presenta con la "Escena" y el "Canto gitano" del Capricho español (1887) de Rimsky Korsakov. Asimis diferencia de la primera canción de Duo Vital, sí que apreciamos reminiscencias de "Mozuka da bien la vuelta" en la canción "Pequeñas Estrellas", donde Shostakovich emplea para la voz el mismo material rítmico que Duo Vital en el tema principal de este movimiento.
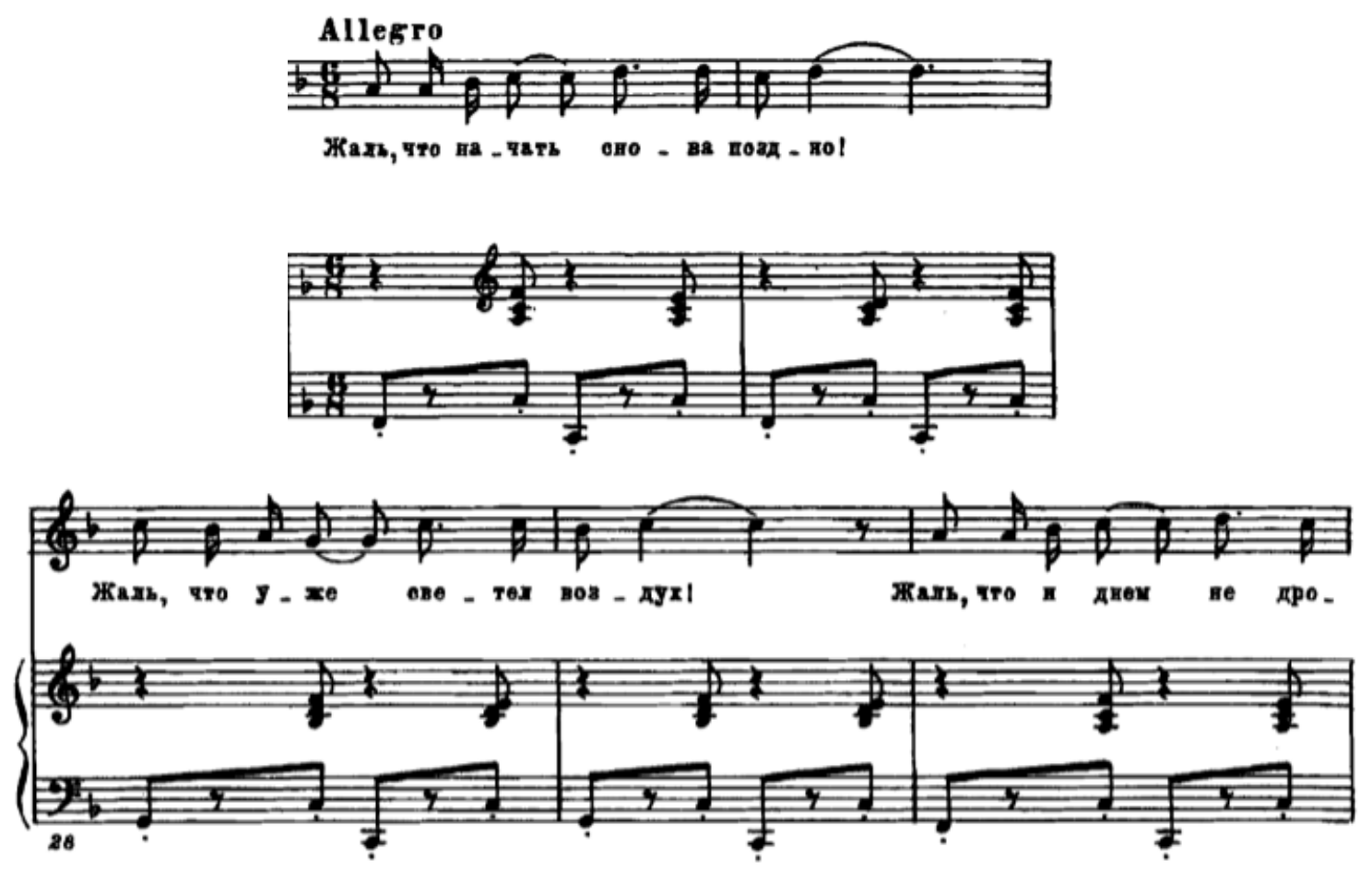

Fig. 3. Tema B, "Pequeñas Estrellas”, cc. 24-28. Canciones españolas (Shostakovich).

A pesar de ello, no podemos afirmar que ésta sea la canción de origen ya que este material rítmico lo apreciamos en muchas jotas montañesas. Sin embargo, es un detalle importante ya que podemos extraer varias conclusiones. Uno de los elementos sonoros que nos recuerdan al folclore español es el tipo de ritmo que utiliza, una reminiscencia a las jotas del norte de España. Además, debemos añadir que el encontrar este tipo de reseña hispánica lo consideramos curioso y algo a tener en cuenta ya que de forma generalizada se entiende por folclore español a la música popular de Andalucía y realmente hay numerosos palos en todas las regiones de España.

En relación con la letra, el texto es el siguiente: 


\section{REFERENCIAS HISPANAS EN OBRAS DE SHOSTAKOVICH DE LA DÉCADA}

DE LOS AÑOS 50

Pequeñas estrellas
Bajo los viejos cipreses,
el mar tranquilo es un espejo de plata.
Voy a mi amada, con mi guitarra,
para enseñarle algunas canciones,
pero no tengo ganas de enseñarle sin recompensa:
tomo un beso por cada nota.
¡Es curioso que por la mañana lo ha aprendido todo,
excepto las notas!
¡Lástima!, es demasiado tarde para volver a empezar.
¡Lástima!, el cielo es ya claro.
¡Lástima!, las estrellas no brillan de día
encima de la bahía...
El cielo infinito está estrellado,
la medianoche está repleta de estrellitas.
Le digo, a mi amada,
los nombres de las estrellas.
Valoro mis conocimientos
y tomo un beso por nombre.
todo excepto las estrellas.
¡Lástima!, es demasiado tarde...

Retomando el núcleo de nuestro trabajo encontramos varios de los elementos que caracterizan la música popular así como otros recursos típicos del folclore español. Podemos destacar el empleo de un ostinato rítmico en el acompañamiento del piano tanto en el tema A como en el tema B la acentuación del pulso débil como conclusión de la canción.

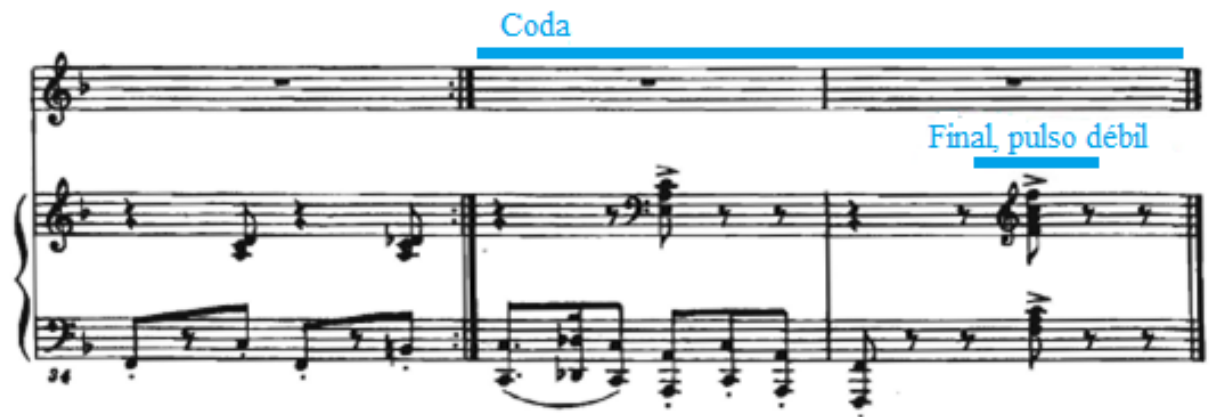

Fig. 4. "Pequeñas estrellas", cc. 34-36. Canciones españolas (Shostakovich).

Durante la introducción del piano encontramos varios elementos empleados con los que se consigue una sonoridad muy española. El primero de ellos es el modo en el que se desarrolla la melodía de la mano derecha mediante el floreo sobre una nota, algo muy 


\section{ANa María Mula Pérez}

característico. Además de este adorno rítmico, armónicamente hace uso de otro recuso muy típico del folclore español y es el empleo del modo frigio. Más concretamente, hace uso de la escala do frigia durante los tres primeros compases de esta introducción, generando la sensación tonal de fa menor (como dominante), que se establece en el cuarto compás. Es decir, a pesar de que la armadura corresponde a la tonalidad de La b Mayor, la música se mueve en la tonalidad de fa menor buscando un determinado color a través de la armonía, algo que estará presente en la mayoría de las canciones.

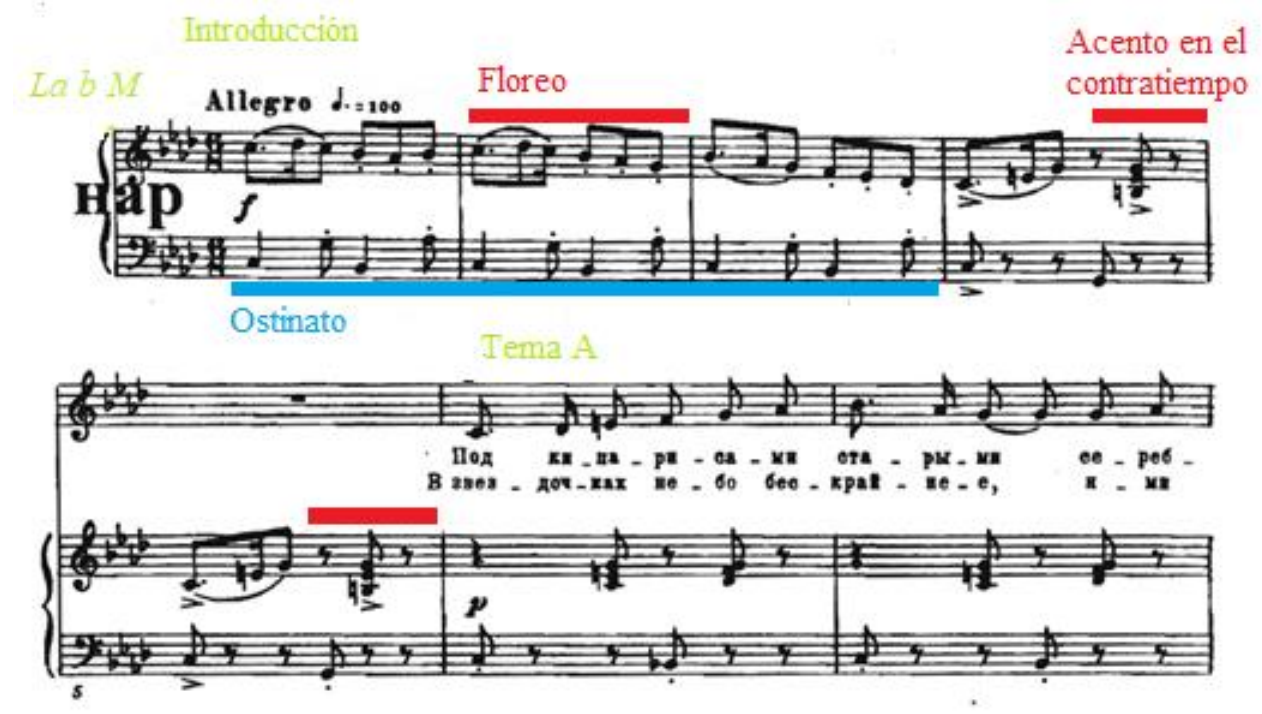

Fig. 5. "Pequeñas estrellas", cc. 1-7. Canciones españolas (Shostakovich).

Otro recurso que nos recuerda a ese aire español es el cambio de los apoyos en el pulso mediante el empleo de compases impares como el 3/8 y la acentuación de los contratiempos (indicado en la imagen anterior).

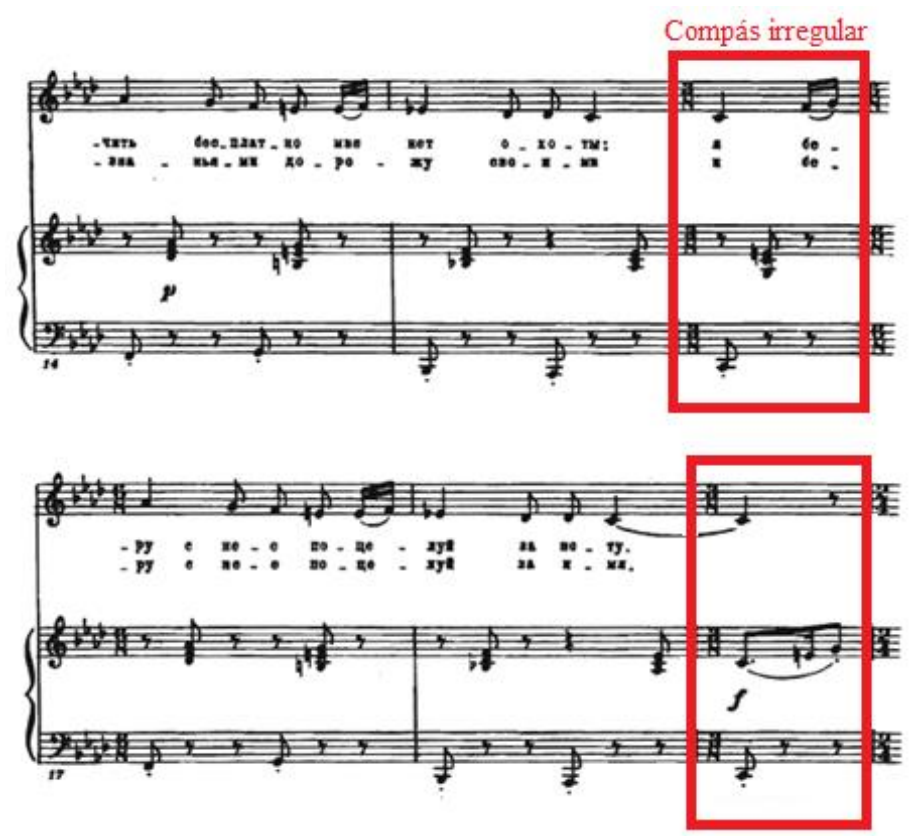

Fig. 6. "Pequeñas estrellas", cc. 14-19. Canciones españolas (Shostakovich). 


\section{REFERENCIAS HISPANAS EN OBRAS DE SHOSTAKOVICH DE LA DÉCADA \\ DE LOS AÑOS 50}

Por último, cabe mencionar el juego con las tonalidades mayores y menores. Como comentábamos, el tema A se encuentra en $L a b M$ pero armoniza constantemente en $f a m$, modulando a $\mathrm{Fa} \mathrm{M}$ en el tema B.
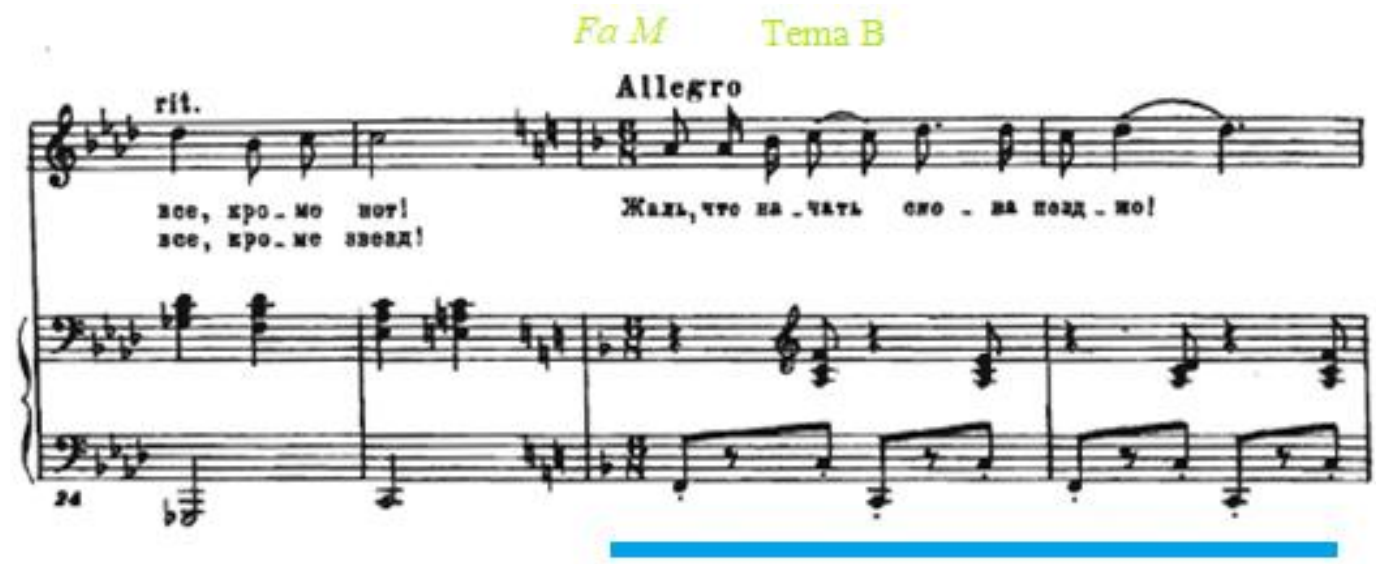

Fig. 7. "Pequeñas estrellas", cc. 24-28. Canciones españolas (Shostakovich).

\section{3.“El primer encuentro”.}

Traducción: S. Bolotin.

Título original "En Samir"

La tercera canción del ciclo está escrita en compás ternario 3/4 y tiene una estructura formada por: introducción, tema A, tema B (Tempo di vals) y tema C. En esta canción Shostakovich también emplea el recurso, que anteriormente comentábamos, del cambio de una tonalidad mayor o menor a otra menor o mayor. Mientras que los temas A y B están escritos en sol menor, termina la canción con el tema C en Sol Mayor. Del mismo modo que en la canción anterior, aparece el empleo del ostinato (aunque esta vez de una forma más trabajada) y el final con la acentuación del pulso débil. Dentro del tema A, el ostinato presenta un patrón rítmico sencillo formado por el constante empleo de negras en la mano izquierda del piano. 


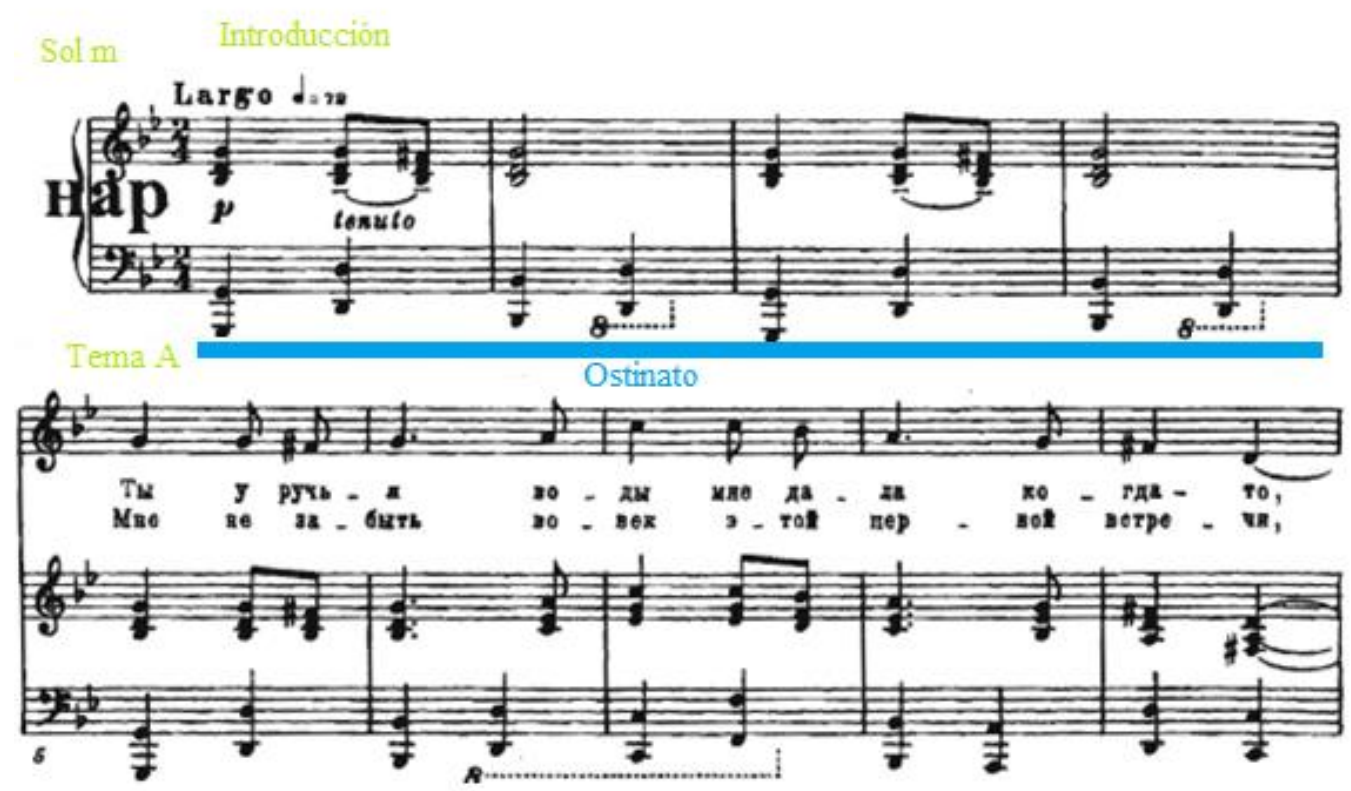

Fig. 8. "El primer encuentro", cc. 1-9. Canciones españolas (Shostakovich).

Sin embargo, el tema B presenta un ostinato más desarrollado, donde la mano izquierda realiza una repetición rítmica de blanca-negra y la mano derecha un ostinato tanto rítmico como armónico con el siguiente floreo:

Tempo di Valse d.zos

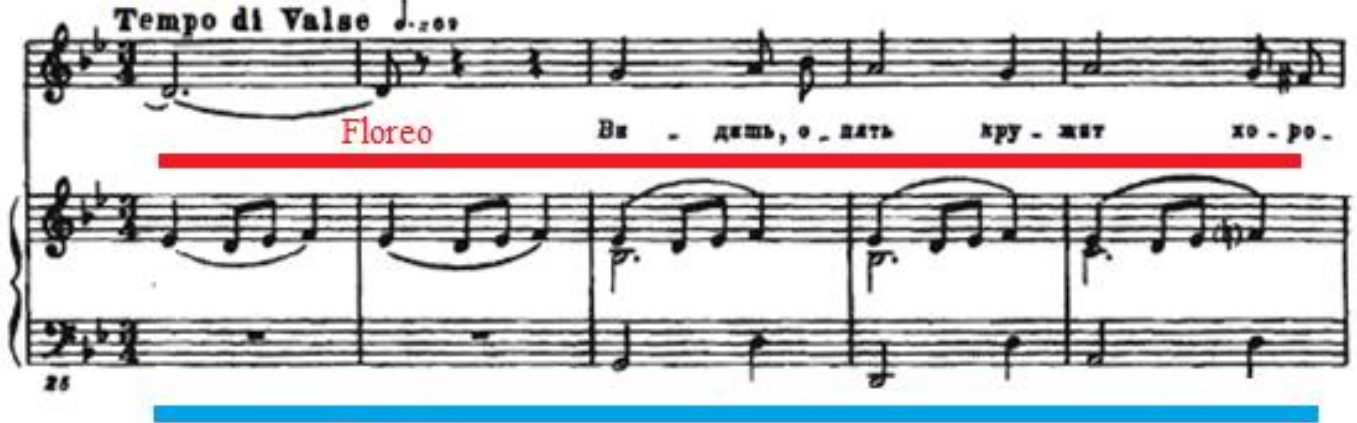

Ostinato

Fig. 9. "El primer encuentro", cc. 25-29. Canciones españolas (Shostakovich).

Del mismo modo, en el tema $\mathrm{C}$ mantiene el ostinato rítmico-armónico del tema $\mathrm{B}$ pero con algún pequeño cambio, dándole mayor sensación de movimiento a la música. 


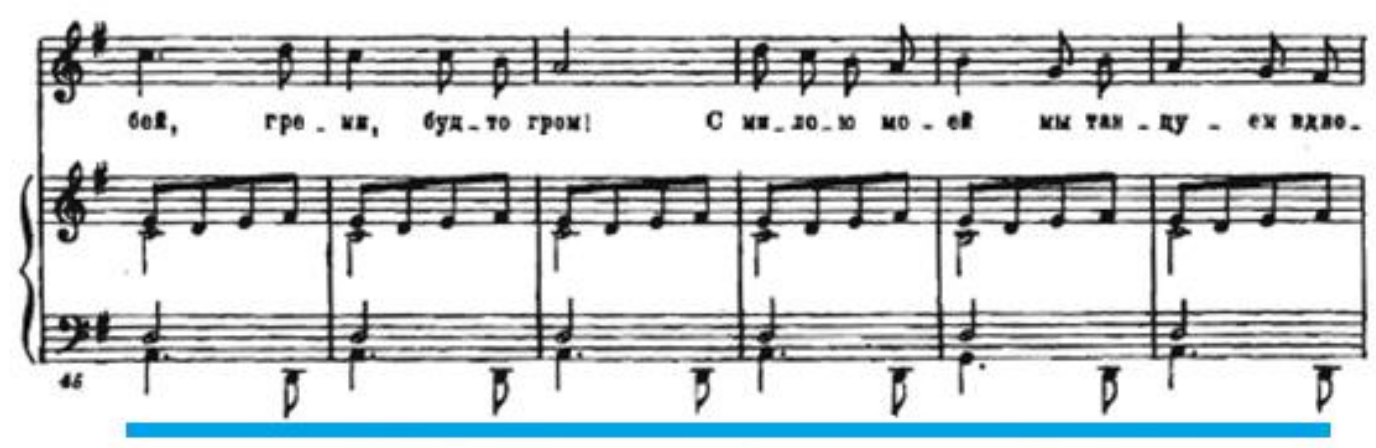

Ostinato

Fig. 10. "El primer encuentro", cc. 45-50. Canciones españolas (Shostakovich).

En cuanto a la melodía, cabe puntualizar la sencillez y el empleo de grados conjuntos, especialmente en el tema $\mathrm{A}$ y en el tema $\mathrm{B}$, uno de los rasgos de la música folclórica que se suma a los puntos hispanos ya comentados. La simplicidad melódica se adecúa a la perfección al texto de la canción, cuya letra en su traducción castellana dicta lo siguiente:

\begin{tabular}{|c|}
\hline $\begin{array}{c}\text { El primer encuentro } \\
\text { Antaño, cerca del arroyo, } \\
\text { me diste agua, } \\
\text { agua fría como la nieve de la montaña. } \\
\text { Más oscura que la noche es tu mirada, } \\
\text { tus trenzas huelen a hierbabuena... } \\
\text { Mira, de nuevo bailan la ronda, } \\
\text { el tamborcillo retumba, } \\
\text { suena y canta. } \\
\text { Cada chico sale al baile con su chica, } \\
\text { la gente les mira, con admiración. } \\
\text { ¡Retumba, pandero, retumba, } \\
\text { como la tempestad! } \\
\text { Bailo con mi amada. } \\
\text { Tu cinta es más azul que el cielo. } \\
\text { ¡Retumba, pandero, retumba! } \\
\text { Nunca olvidaré este primer encuentro, } \\
\text { las palabras dulces, } \\
\text { tu mano morena y el brillo de tus ojos negros... } \\
\text { En este momento sé que te amo, } \\
\text { y que te amaré para siempre. } \\
\text { Mira, de nuevo... } \\
\text { Retumba, pandero... }\end{array}$ \\
\hline
\end{tabular}




\section{ANa María Mula PÉrez}

\section{4."Ronda".}

Traducción: T. Sikorskaya.

Título original: "Ronda".

En la canción "Ronda" encontramos nuevos elementos españoles que anteriormente no habían aparecido. Esta canción posee una estructura con introducción, tema A y tema B. El tema A está escrito en compás de 3/8 y en la tonalidad de Sol b Mayor, mientras que el tema B (meno mosso) se encuentra en Mi b Mayor y en compás de 2/4. De nuevo, encontramos el tratamiento del color a través de la armonía. A pesar de su armadura, en el tema A se mueve constantemente en otras tonalidades, como por ejemplo el empleo de Sol Mayor para la introducción. En relación con la letra el texto presenta el siguiente contenido:

\begin{tabular}{|c|}
\hline $\begin{array}{c}\text { Ronda } \\
\text { A nuestra puerta está la ronda, } \\
\text { ha llegado el tiempo de júbilo. } \\
\text { ¡Ven, rápido, y baila conmigo, } \\
\text { clavelito colorado! } \\
\text { En el silencio de la luna } \\
\text { resuena el murmullo del arroyo. } \\
\text { Dame la mano, querida, amor, } \\
\text { clavelito colorado. } \\
\text { La calle parece un jardín de flores. } \\
\text { Suenan las sonrisas, } \\
\text { brillan los ojos. } \\
\text { La ronda gira y canta, } \\
\text { las parejas giran. } \\
\text { Es bóveda celeste luce sus astros de plata, } \\
\text { la alegre fiesta de las primeras flores, } \\
\text { es la fiesta de nuestro amor. } \\
\text { Las sombras de los almendros juegan, } \\
\text { en la luz de la luna, bajo la ventana. } \\
\text { ¿Cuándo vendrás a mí, } \\
\text { mi dulce flor de primavera? } \\
\text { Coge una rama de almendro, } \\
\text { dámela, como prueba de tu amor, } \\
\text { ¡Mi dulce flor de primavera! } \\
\text { La calle parece un jardín... }\end{array}$ \\
\hline
\end{tabular}




\section{REFERENCIAS HISPANAS EN OBRAS DE SHOSTAKOVICH DE LA DÉCADA DE LOS AÑOS 50}

Como en las canciones anteriores, no falta la presencia de un ostinato. En la introducción del piano la mano izquierda repite constantemente el patrón rítmico

y en la mano derecha La novedad que comentábamos la encontramos en este último. Una de las características de la música española es la búsqueda de una analogía con instrumentos típicos del país. En muchas composiciones de origen español, o inspiradas en España, podemos encontrar el empleo de una instrumentación guitarrística, es decir, presentan una orquestación de tal forma que emule los recursos técnicos y sonoros de la guitarra con otros instrumentos. En este caso, con este material rítmico consideramos que pretende simular un recurso muy flamenco de la guitarra, el famoso rasgueo.

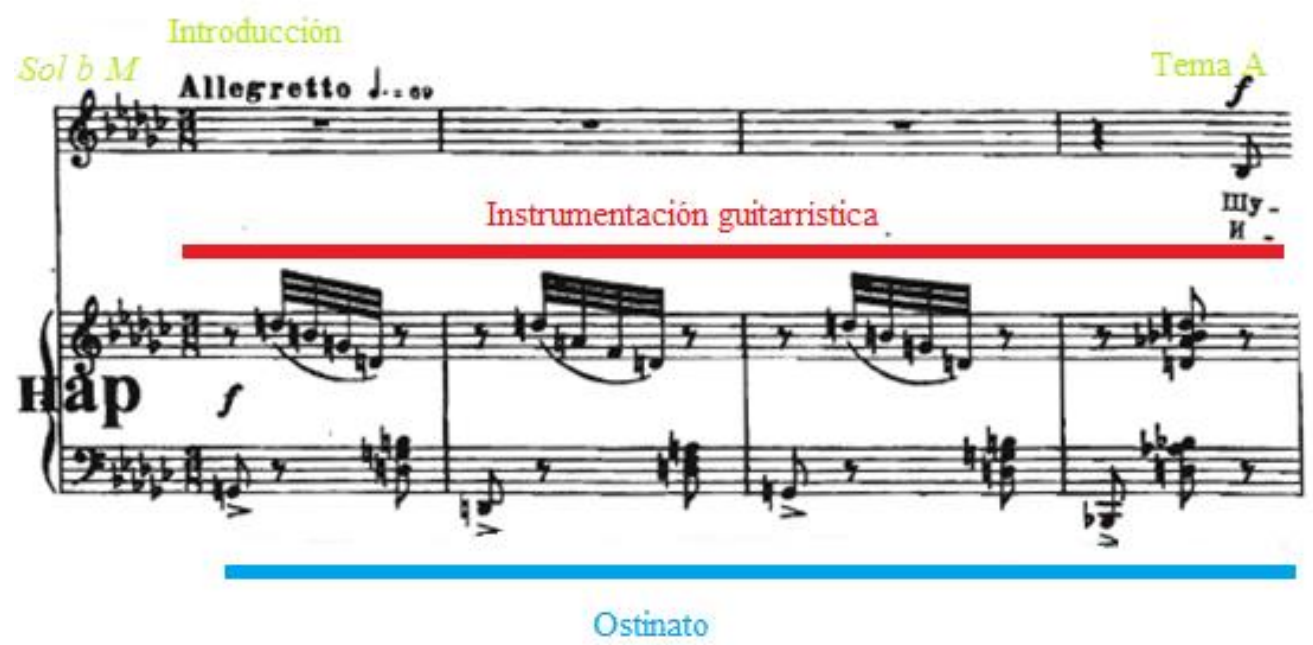

Fig. 11. "Ronda", cc. 1-4. Canciones españolas (Shostakovich).

Dentro del tema A también es destacable el uso del floreo en la voz, tanto en los momentos cadenciales como en el desarrollo de la melodía. Es decir, destaca el trabajo del adorno en el melisma dándole un toque más virtuosístico con estos giros en las notas.

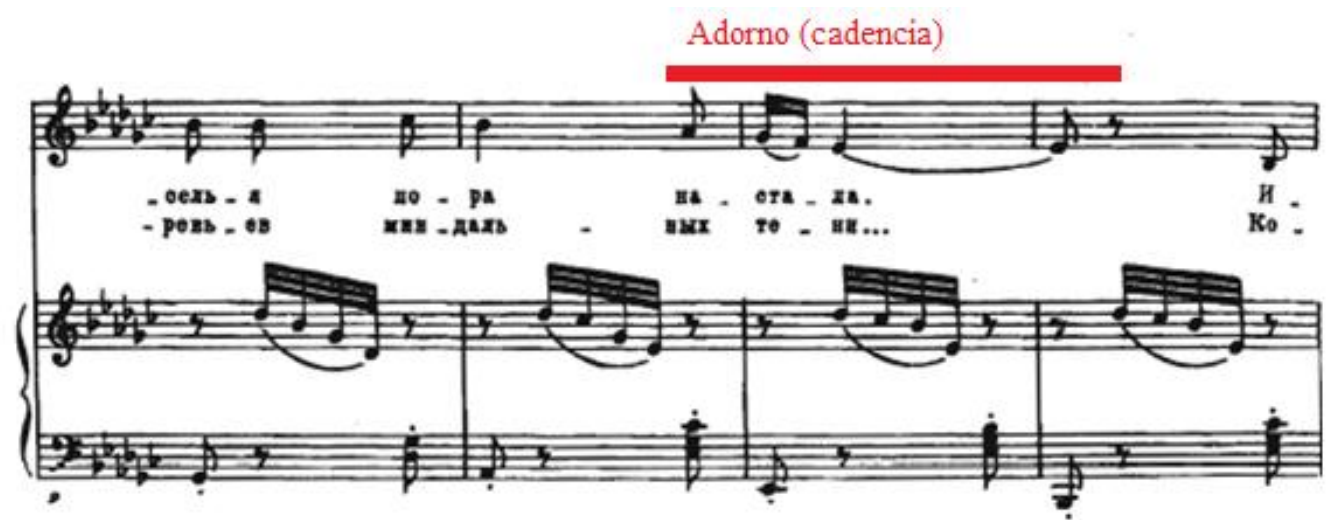

Fig. 12. "Ronda", cc. 5-8. Canciones españolas (Shostakovich). 


\section{ANa María Mula Pérez}

De nuevo, podemos apreciar el empleo del modo frigio, tan habitual del cante flamenco. A pesar de que la voz se mantenga tonal, en el compás 22 el acompañamiento del piano se mueve armónicamente de forma modal.
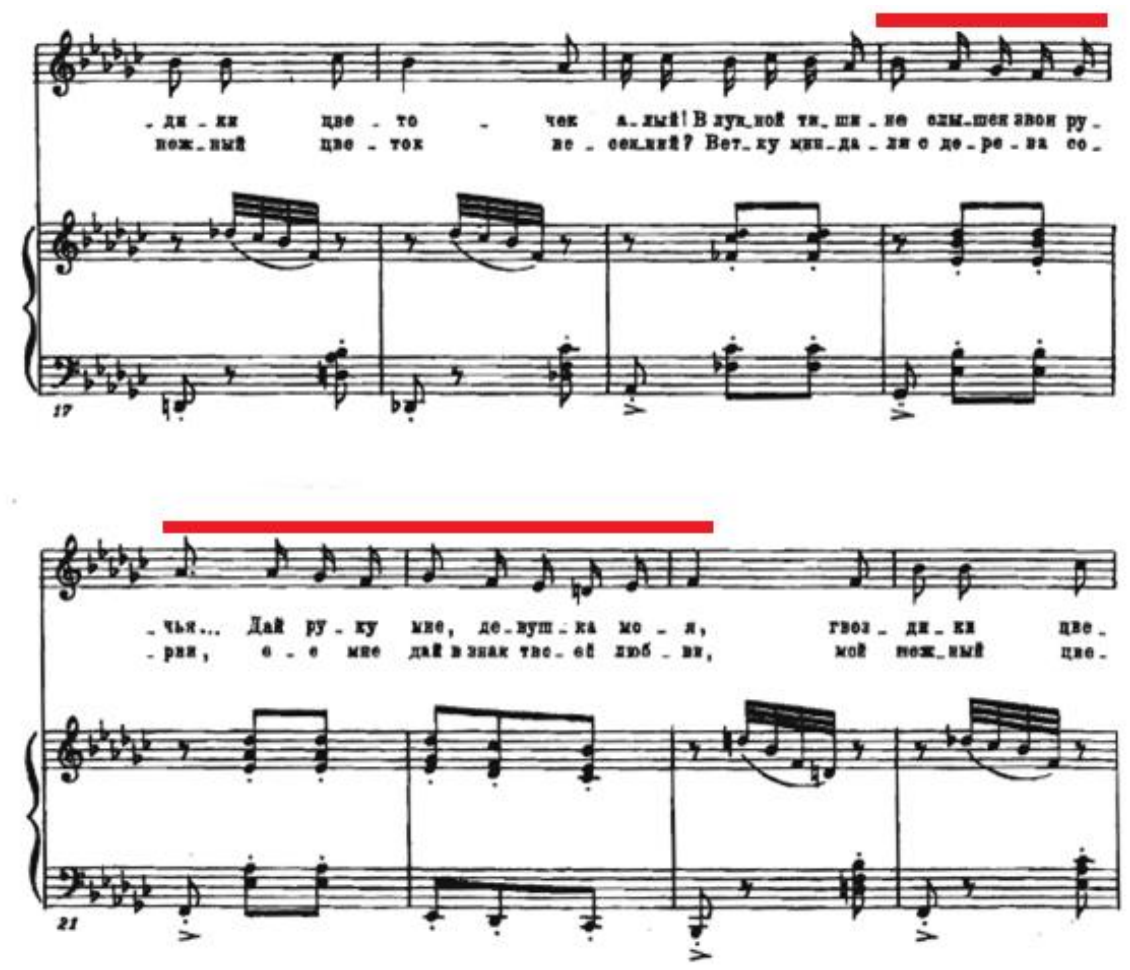

Fig. 13. "Ronda", cc. 21-24. Canciones españolas (Shostakovich).

Al igual que el tema $\mathrm{A}$, el tema $\mathrm{B}$ presenta también su propio ostinato

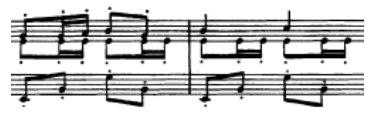

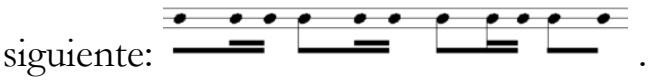


REFERENCIAS HISPANAS EN OBRAS DE SHOSTAKOVICH DE LA DÉCADA

DE LOS AÑOS 50

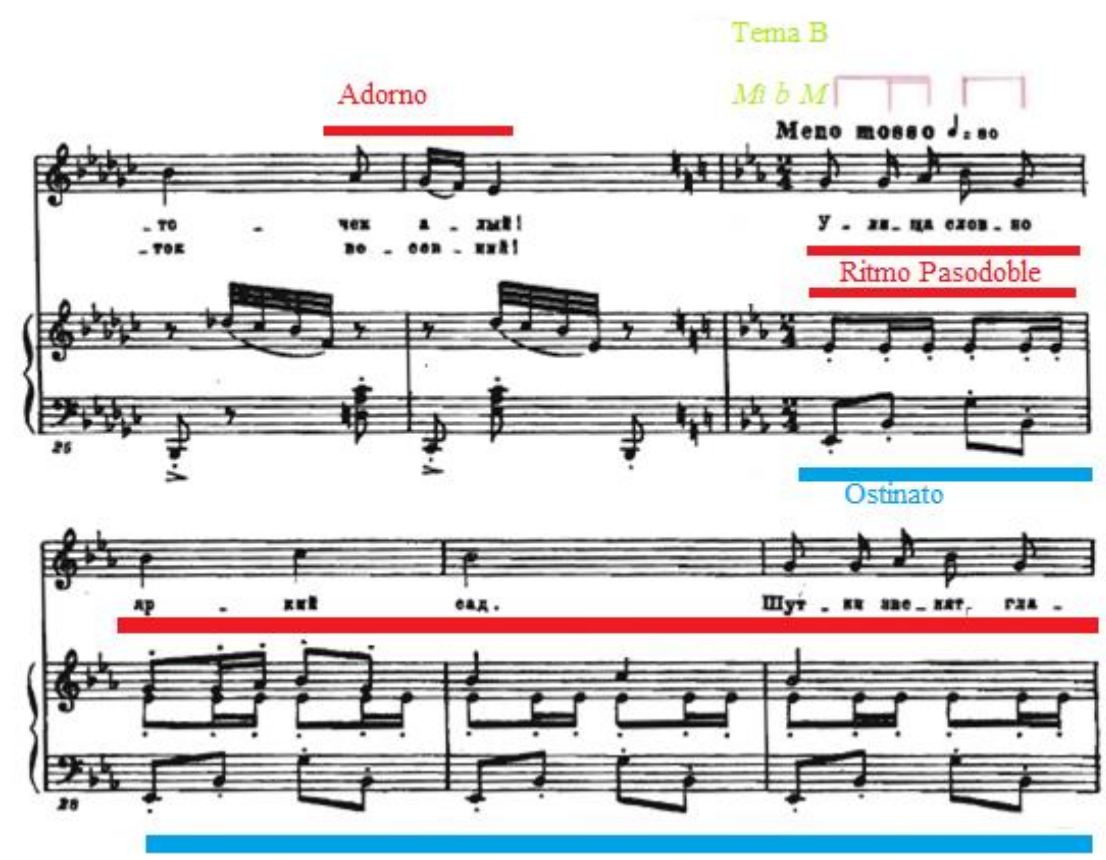

Fig. 14. "Ronda", cc. 25-30. Canciones españolas (Shostakovich).

5. “La muchacha de los ojos negros".

Traducción: T. Sikorskaya.

Título original: Morena salada.

Esta canción, escrita en Do Mayor y en compás de 2/4, presenta una estructura clásica: introducción, tema $\mathrm{A}$, tema $\mathrm{B}$, tema $\mathrm{A}$. El ostinato que esta vez presenta el tema $\mathrm{A}$ está escrito de tal manera que podríamos considerarlo una referencia al bajo Alberti.

Introducción

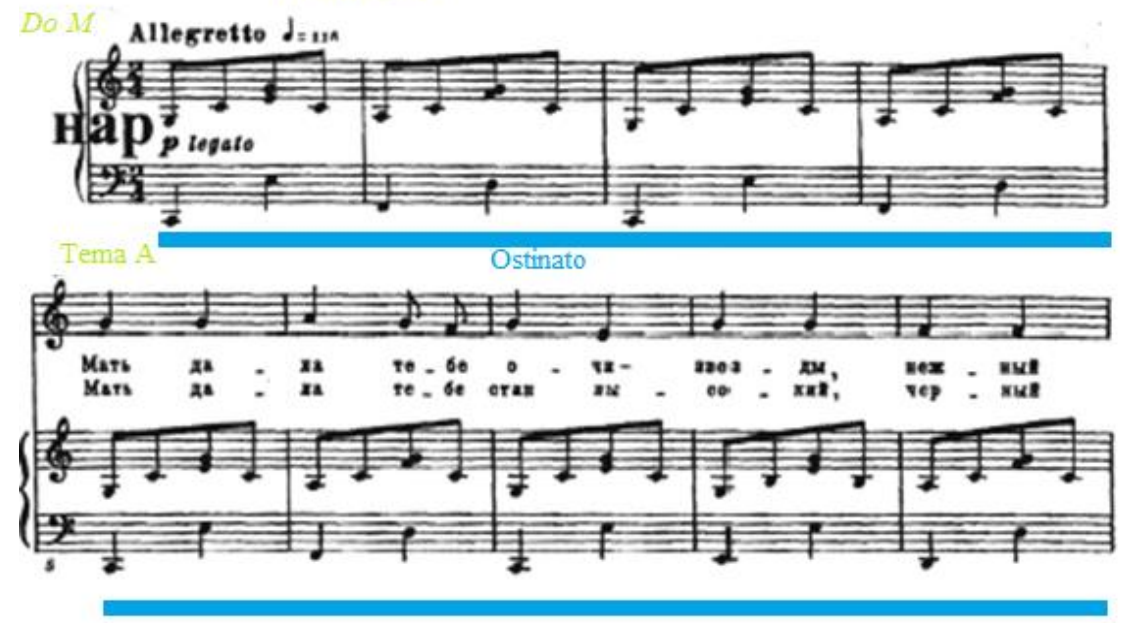

Fig. 15. "La muchacha de los ojos negros", cc. 1-9. Canciones españolas (Shostakovich). 


\section{ANa María Mula Pérez}

El tema B también presenta este mismo ostinato, aunque desarrollado de una forma algo diferente.

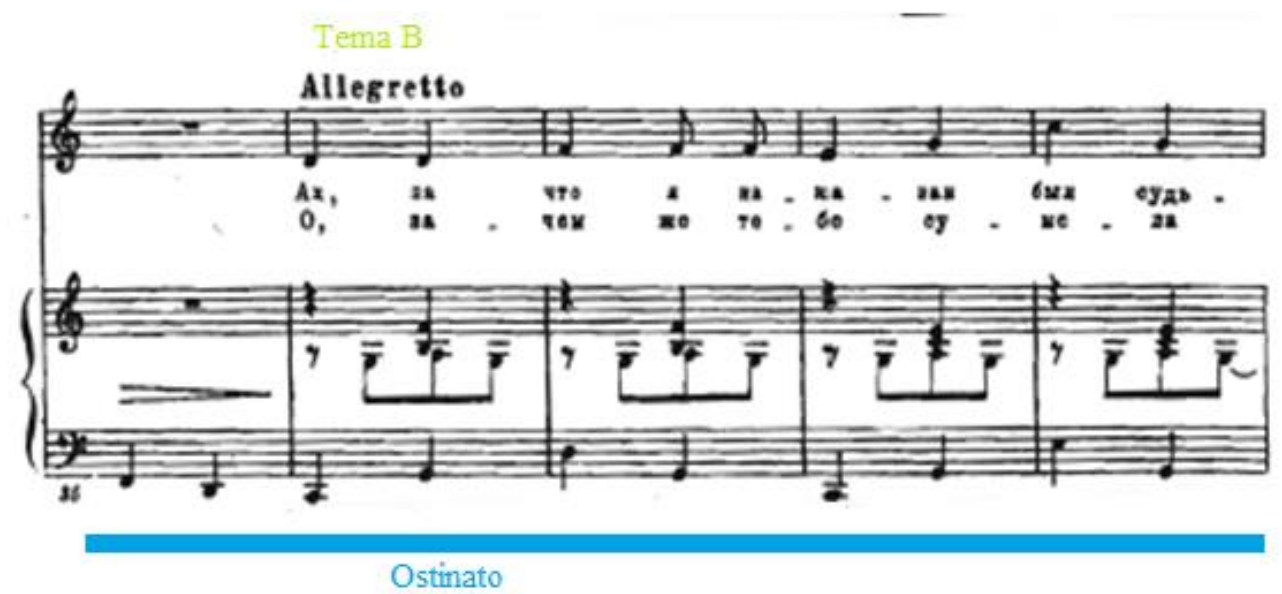

Fig. 16. "La muchacha de los ojos negros", cc. 35-39. Canciones españolas (Shostakovich).

En cuanto a la melodía es sencilla y está formada por grados conjuntos. Presenta una ausencia de dominante, con lo que logra que suene a algo lejano, muy acorde con el contenido del texto, en el que el autor describe a su amada. Este carácter improvisatorio podría ser entendido de nuevo como una referencia a lo tradicional, todo ello en torno al texto de la canción:

\begin{tabular}{|} 
La muchacha de los ojos negros \\
Tu madre te dio los ojos estrellados, \\
las mejillas de un tierno color oscuro, iquerida! \\
Solo, me pierdo sin ti en la noche profunda \\
con dolor en mi corazón, iquerida! \\
¿Por qué he sido castigado por el destino? \\
¿Por qué te he conocido? \\
Moriré de amor, \\
si tú no me amas, iquerida! \\
Eres alta y delgada, como tu madre, \\
el resplandor negro de tu pelo rebelde, iquerida! \\
¡Maldita la suerte cruel, \\
el dolor y el tormento de mi alma, querida! \\
Oh, ¿Por qué tu madre pudo darte tal belleza \\
para contrariarme? \\
Moriré, loco de amor, \\
si tú no me amas, iquerida!
\end{tabular}




\section{REFERENCIAS HISPANAS EN OBRAS DE SHOSTAKOVICH DE LA DÉCADA \\ DE LOS AÑOS 50}

\section{6. "Sueño".}

Traducción: S. Bolotin y T. Sikorskaya.

Título original: desconocido.

Esta vez nos encontramos con un compás de 6/8 en la tonalidad de Mi b Mayor y con una estructura formada por introducción, tema A, tema B, tema A y coda. En el tema A encontramos un ostinato armónico-rítmico sobre la nota mi. Rítmicamente, el material de la mano izquierda del piano es sencillo , mientras que en la mano derecha está más desarrollado a través del empleo del adorno o floreo, que no siempre busca el primer pulso texto, ya que nos ubica en el mar, por lo que la síncopa sobre el primer tiempo da la sensación de continuo movimiento simulando las olas. Además, este ostinato irá desarrollándose a medida que avance el tema $\mathrm{A}$, transformándose en semicorcheas e incluso intercambiando el ostinato en cada una de las voces del piano.

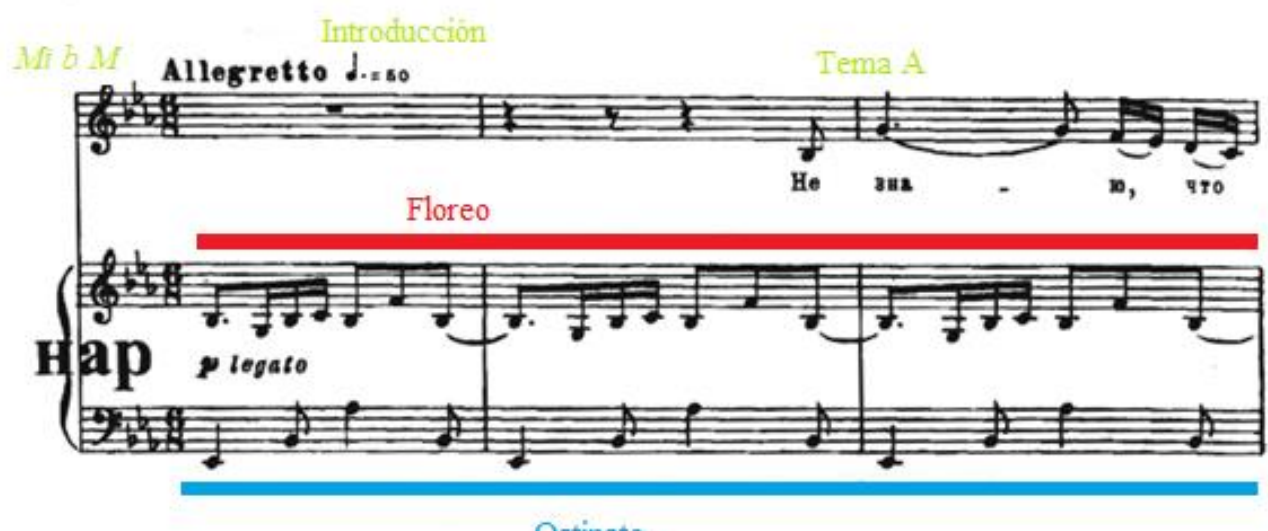

Ostinato

Fig. 17. "Sueño", cc. 1-3. Canciones españolas (Shostakovich).

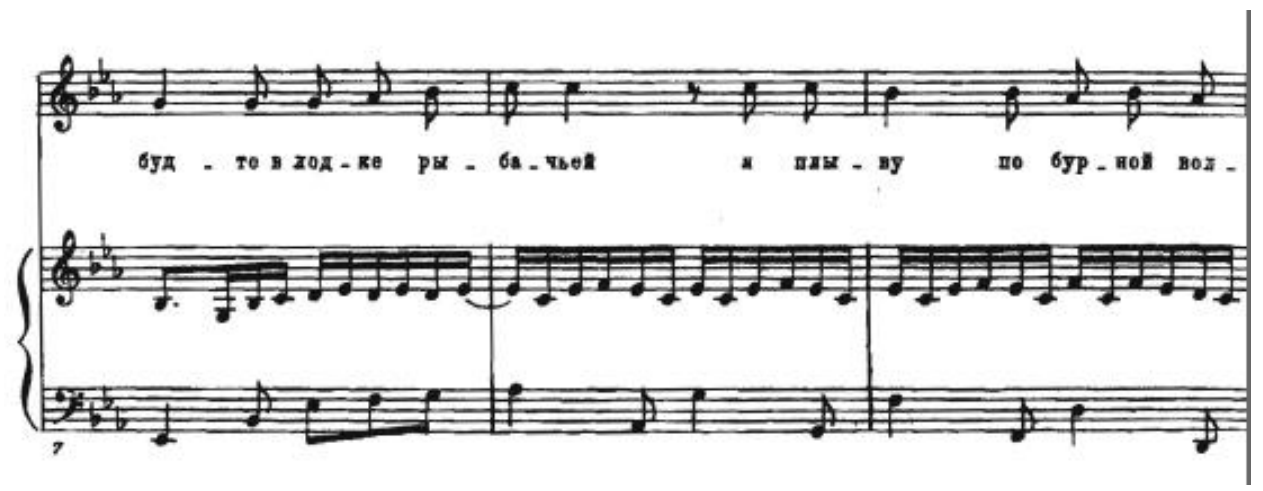

Fig. 18. "Sueño", cc. 7-9. Canciones españolas (Shostakovich). 
ANA MARÍA MUla PÉREZ

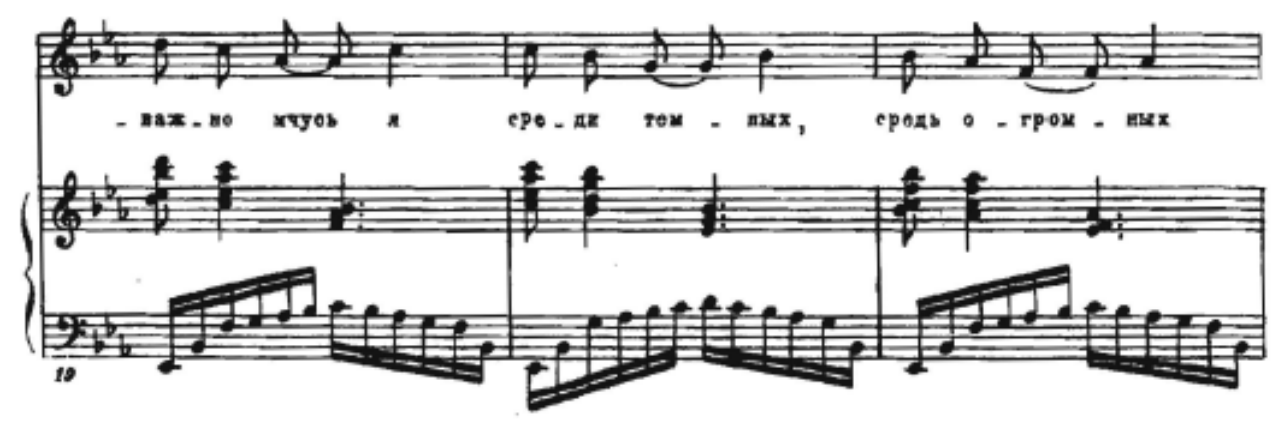

Fig. 19. "Sueño”, cc. 19-21. Canciones españolas (Shostakovich).

Por lo que respecta a la melodía, mientras que en el tema $\mathrm{A}$ encontramos un melisma sencillo, el tema B presenta un material más trabajado en el que, mediante el empleo del adorno o floreo, adopta un carácter más virtuosístico gracias a la presencia de esos giros entre las notas.

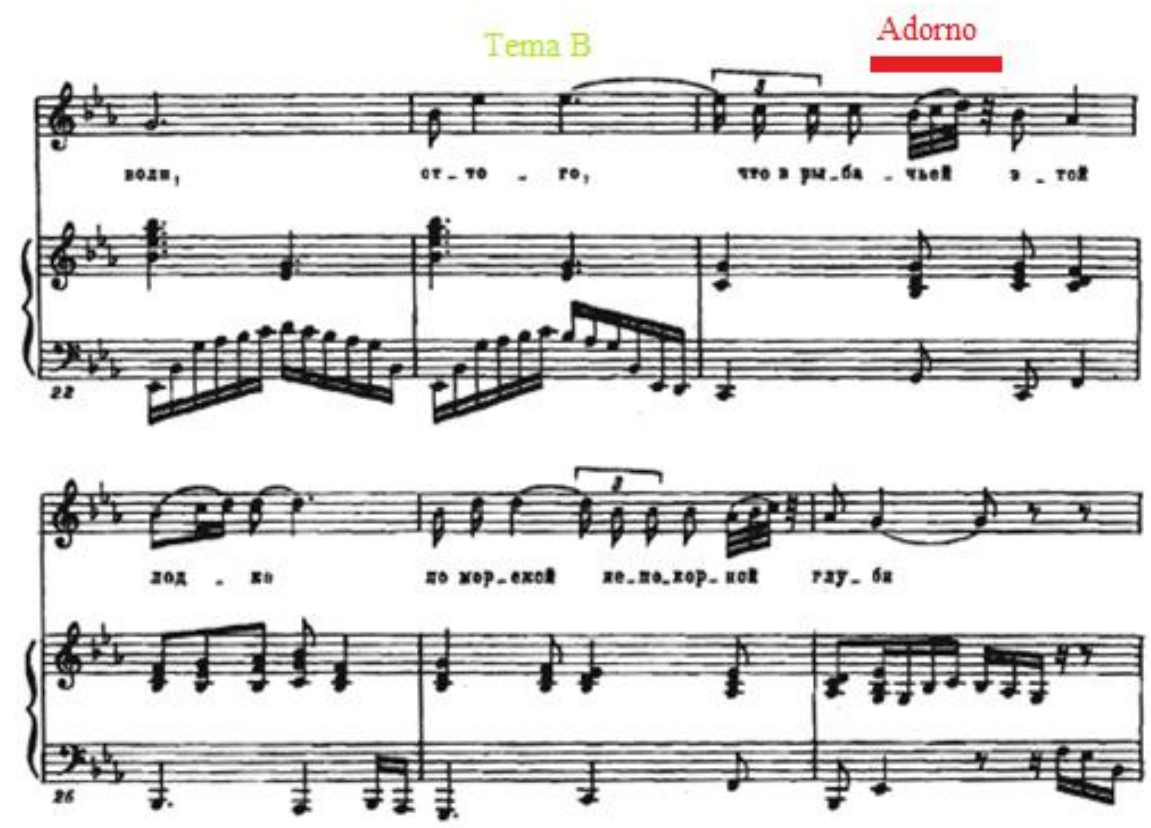

Fig. 20. "Sueño", cc. 1-3. Canciones españolas (Shostakovich).

Con relación al texto, éste es el contenido de "Sueño" en castellano: 


\section{REFERENCIAS HISPANAS EN OBRAS DE SHOSTAKOVICH DE LA DÉCADA \\ DE LOS AÑOS 50}

Sueño
No sé qué significa.
He tenido un sueño maravilloso:
en una barca de pescar,
deslizo sobre una ola impetuosa.
Una barquilla sin remos,
los he perdido.
Las olas espumantes, se irritan
y quieren hundir mi barca,
pero con coraje,
remo rápidamente entre las olas oscuras y enormes
porque en esta barca de pescar,
orgullosa, tú estás conmigo,
iy tú también me amas!
Oh, mi paloma,
mira bien, cómo remo
por encima de la incontenible profundidad marina,
rápidamente sobre el mar en mi barca frágil,
ipobre muchacho que te ama tanto!

Por lo tanto, después de realizar el análisis anterior sobre cada una de las canciones y a pesar de desconocer las obras originales sobre las que Shostakovich armonizó o compuso estas seis, gracias a la presencia de elementos que caracterizan el folclore en general y a la identificación de recursos típicos de la música española, podemos reafirmar la hipótesis que defiende la inspiración del compositor en canciones populares españolas, así como catalogarlas como una de las obras más representativas de reminiscencias hispanas dentro de las composiciones de Shostakovich.

\section{3. "VALS NÚM. 2”, SUITE PARA ORQUESTA DE VARIEDADES (C. 1956).}

Por último y terminando con las obras de los años cincuenta, otro ejemplo claro de la presencia de melodías populares de carácter español en la obra de Shostakovich es el "Vals núm. 2" de la Suite para Orquesta de Variedades. Durante muchos años se pensó, erróneamente, que este vals pertenecía a la Suite de jazz núm. 2 (1938) cuya partitura se perdió durante la II Guerra Mundial. Sin embargo, en realidad el citado vals pertenece a una obra bastante posterior, la Suite para Orquesta de Variedades, formada por una recopilación de piezas de otras de sus obras (principalmente de bandas sonoras musicales) realizada por Shostakovich después de $1956^{5}$. Concretamente, el célebre "Vals núm. 2" que tomamos como objeto de estudio en esta ocasión, popularizado por su aparición en la película Eyes wide shut (1999, Stanley Kubrick), procede de una película del año 1955 para la cual Shostakovich compuso su banda sonora musical, El primer escalón (Lee, 2013: 231). 


\section{ANA MARÍA MUla PÉREZ}

Aunque ya hemos mencionado que no pertenece a la Suite de jazz núm. 2, cabe señalar que el vals no muestra mucho parecido con el jazz, sino con la tradición vienesa de valses al ritmo de los de Strauss y con la música ligera que tanta fama tuvo en el siglo XX como parte de las músicas populares urbanas logrando un gran éxito desde el punto de vista social por su participación en la vida cotidiana de la población. De hecho, las similitudes de la composición de Shostakovich con la música ligera no hace sino significar un punto de conexión con el público, pues los estilos musicales de carácter melódico y sencillas armonías lograron una mayor aceptación que el jazz, estilo que, a pesar de su origen, se convirtió en uno de los símbolos de los círculos elitistas y acabó cosechando poca aceptación por parte de la población en general.

En cuanto al aspecto musical, debemos destacar la gran similitud que presenta el "Vals núm. 2" con una canción tradicional española titulada "Una mañana de mayo, yo te daré". Se trata de un tema popular del que se ignora su autor, su fecha y su lugar de origen. En realidad, tal y como comentábamos con las Canciones españolas, resulta habitual que los repertorios de las melodías populares no recojan los datos de aquel que creó dichas canciones, pues el elemento más significativo de la música popular de carácter tradicional o urbano es su inserción en la realidad social de un pueblo. Hoy en día, esta canción se incluye dentro del repertorio tradicional que interpretan las tunas y antiguamente constituía parte de los bailes y canciones de niños, pasando posteriormente a formar parte del repertorio de las canciones interpretadas por los legionarios y falangistas durante la guerra, quienes jugaron con el acrónimo de la palabra "café" (Camaradas, Arriba Falange Española). Al parecer, ya hacían uso de éste en los años previos a la guerra civil y siempre con gran discreción para evitar que se conociera su significado, ya que era muy recurrido para advertir de posibles peligros (Duthel, 2015: 815).

Como decíamos, el "Vals núm. 2" fue compuesto por Shostakovich para la película El último escalón en 1955 y, aunque se desconozca la fecha de origen de la canción española, sí se sabe que se cantaba durante la guerra. Además, algunos testimonios orales a los que hemos accedido a través de entrevistas confirman su aprendizaje en la escuela, habitualmente impartidas dentro de las asignaturas complementarias que solían estar dirigidas por monitores (en el caso de las escuelas masculinas, del Frente de Juventudes) (Sánchez Rodríguez, 2015: 319-350). Por ello, podemos afirmar que la canción "Yo te daré" sería cronológicamente anterior a este vals.

En cuanto a lo concerniente con Shostakovich, algunos autores defienden la tesis, al igual que con las Canciones españolas, de que pudo tener conocimiento de ella a través de los niños españoles que llegaron a Rusia durante la Guerra Civil española ${ }^{6}$. Sin embargo, debemos puntualizar una observación que podría poner tela de juicio esta hipótesis, pues la introducción del "Vals" de la Suite de jazz núm. 1 (1934) es idéntica a la del "Vals núm. 2"

${ }^{6}$ Cfr. <http:/ / contraplano71.blogspot.com.es/2014/02/vals-n-2-de-shostakovich.html> [Última consulta: 14 de marzo de 2018]. Cfr. <http://eratoyeuterpe.blogspot.com.es/2011/01/el-baile-de-la-vida.html> [Última consulta: 14 de marzo de 2018]. 


\section{REFERENCIAS HISPANAS EN OBRAS DE SHOSTAKOVICH DE LA DÉCADA \\ DE LOS AÑOS 50}

aquí reseñado y la mayor emigración española a Rusia debido al estallido de la Guerra Civil se produjo entre los años 1937 y 1938.

A continuación, se incluye un fragmento del "Vals núm. 2" de Shostakovich (arreglo para piano), una transcripción de la canción popular "Yo te daré" y otro fragmento del vals de la Suite de jazz con el fin de ilustrar las posibles similitudes o diferencias entre cada una de las composiciones.
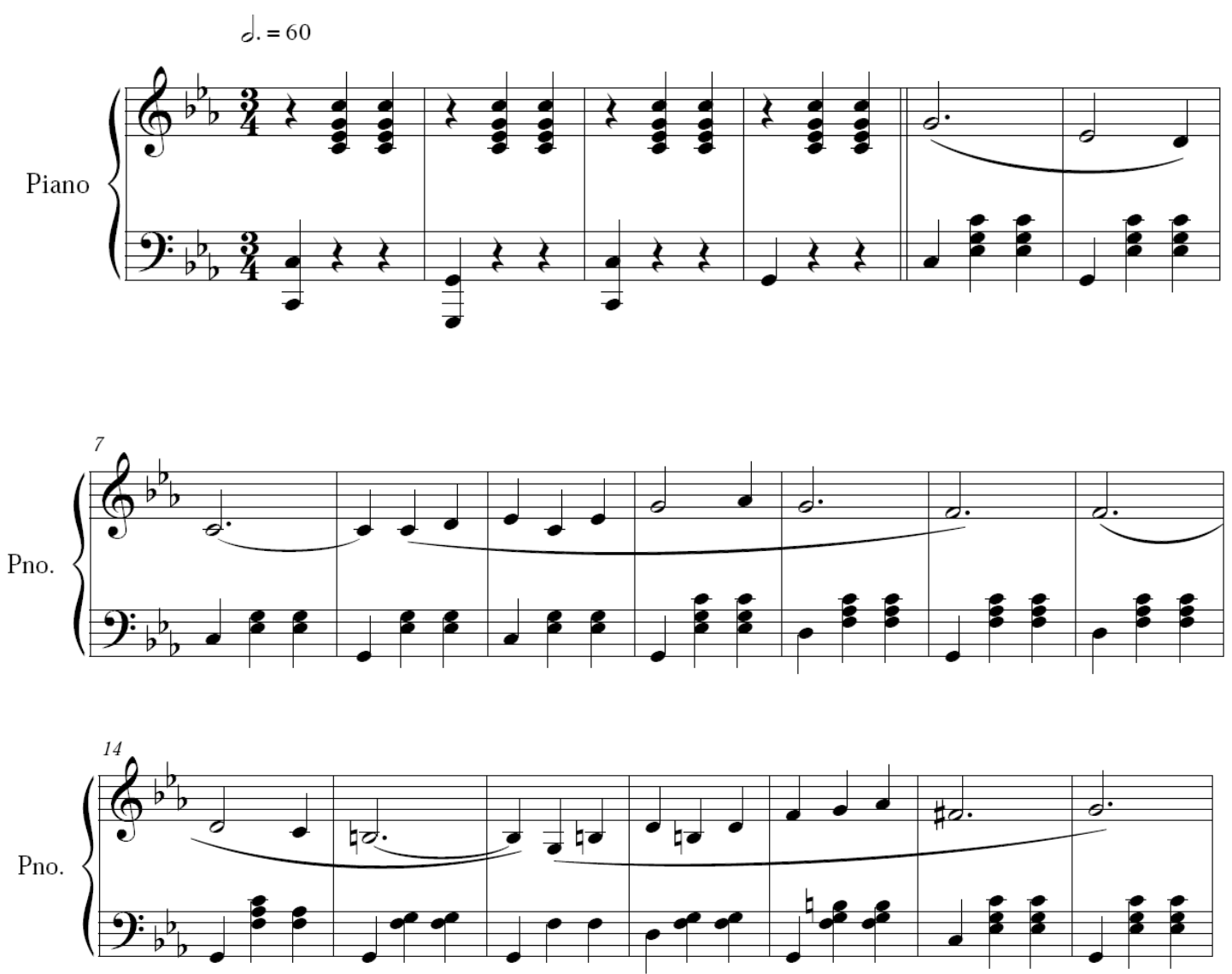

Fig. 21. "Vals núm. 2" de la Suite para orquesta de variedades, Shostakovich. Transcripción, Blanca García Nieto. 
ANA MARÍA Mula PÉREZ
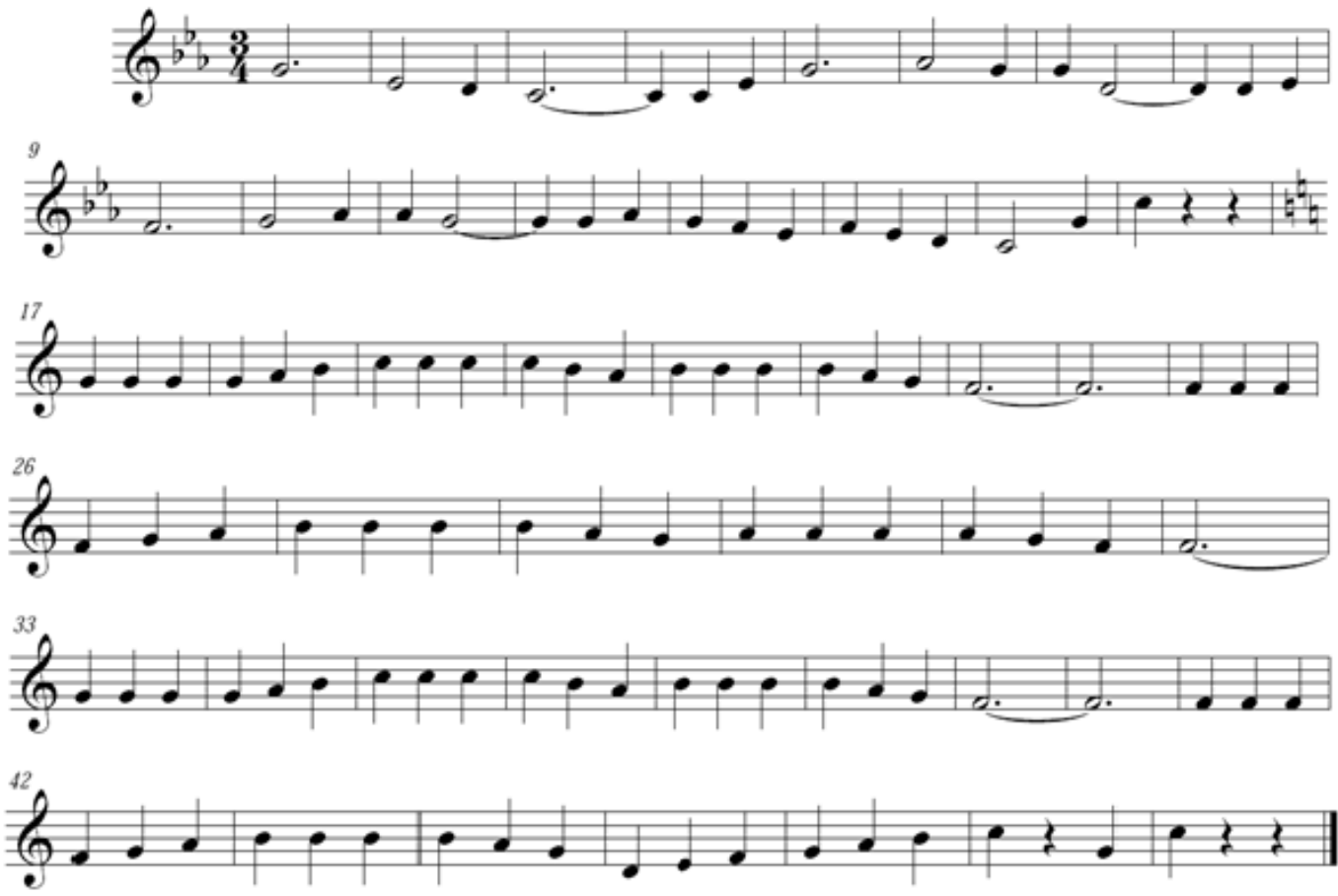

Fig. 22. "Una mañana de mayo, yo te Daré".

Transcripción, Blanca García Nieto.
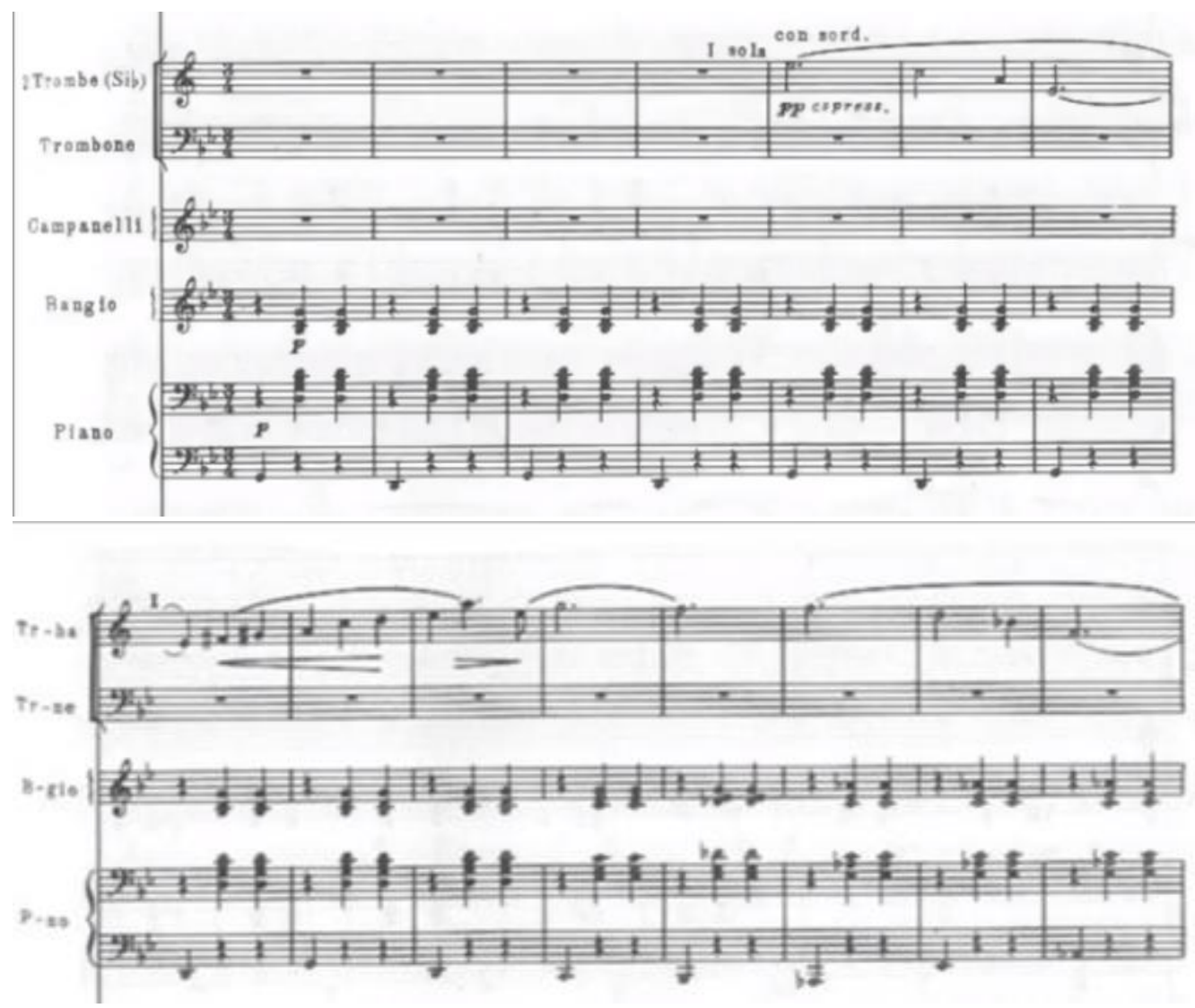

Fig. 23. "Vals" de la Suite de Jazz núm. 1. Shostakovich. 


\section{REFERENCIAS HISPANAS EN OBRAS DE SHOSTAKOVICH DE LA DÉCADA DE LOS AÑOS 50}

Como se puede comprobar tras una observación de las partituras del "Vals núm. 2" y la canción "Yo te daré", son varias las similitudes que se observan entre ambas. Además de compartir la misma tonalidad $(d o m)$ y el compás ternario, también se observan claras conexiones desde el punto de vista melódico y armónico. El elemento más evidente al respecto coincide con los intervalos iniciales del motivo, como se observa en el intervalo de tercera menor descendente resultante entre los dos primeros sonidos hacia la tónica (un do 3) con la inserción de una nota de paso previa. A pesar de que después de este comienzo se observan algunas pequeñas diferencias, la estructura armónica sigue siendo la misma.

Sin embargo, el "Vals núm. 1" difiere en bastantes más aspectos con el "Vals núm. 2". El primero de ellos y más evidente nada más observar la armadura es la tonalidad, que en este caso emplea sol $m$ en lugar de do $m$. Por otro lado, a pesar de que durante los tres primeros compases el tema principal (del trombón) presenta la misma secuencia de terceras y cuartas descendentes, en el cuarto compás la relación de intervalos es completamente diferente a la del "Vals núm. 1".

Por lo tanto, más allá de la controversia que pueda generar el parecido del inicio del "Vals núm. 2" con el "vals" de la Suite de jazz. núm. 1, queremos subrayar en esta composición la reminiscencia hispana dentro de la obra de Shostakovioch, ya que las similitudes musicales son mucho más evidentes en la canción española "Yo te daré" que con el "Vals" de la Suite de jazz núm. 1.

\section{CONCLUSIONES}

Teniendo en cuenta todo lo anteriormente expuesto, podríamos decir que, a pesar de que la presencia de referencias hispanas insertas en composiciones musicales de autores rusos no es algo novedoso, en torno a la figura de Shostakovich sí que resulta complicado justificar la existencia de una relación directa entre el compositor y el país hispano ya que no viajó nunca a nuestro país, o por lo menos no conocemos ninguna referencia que haga alusión a ello. Pero, aun así, se pueden justificar las referencias sonoras de carácter español en torno a tres direcciones.

Por un lado, España a lo largo de la historia de la música ha servido como inspiración a numerosos compositores, incluyendo los de nacionalidad rusa. Eso se puede comprobar con un acercamiento al legado de músicos vinculados con el nacionalismo. Por otra parte, más allá del acercamiento a España como tema de inspiración, en el siglo XX se produce una gran circulación de modelos sonoros y de melodías por toda Europa que se van implantando en las distintas sociedades. En tercer lugar, dado el papel que desempeñó la Unión Soviética con la Guerra Civil Española, siendo uno de los principales países que acogió a la población exiliada por el conflicto, podríamos considerar que la inmigración tuvo también un papel determinante en esta relación del compositor con España.

Independientemente del tipo de acercamiento que pudo tener Shostakovich con la cultura musical española, sí que podemos afirmar la identificación de elementos vinculados con España en algunas obras de Shostakovich pertenecientes a la década de los años 50, ya 


\section{ANA María Mula PÉREZ}

sea a través de la temática ("Adiós Granada"), ya sea mediante la incorporación de melodías tradicionales españolas (el "Vals núm.2”), del empleo de recursos musicales típicos del folclore español ("Tarantella" y Canciones españolas) o por poseer varios de los elementos anteriores ("Adiós Granada").

En este sentido, y tras el estudio conjunto y específico de estas obras de Shostakovich que incluyen ciertas referencias sonoras vinculadas con la Península Ibérica, podemos extraer varias conclusiones adicionales. Consideramos que la presencia de elementos que vinculan estas obras del compositor con España no implica una relación directa con el país hispano, sino con la popularización de las melodías o de los representantes de la cultura. Es improbable que Shostakovich conociera las canciones que se interpretaban en España como parte de la cultura popular. Más bien, podría decirse que debido a la emigración de españoles al país soviético esas melodías se popularizaron y pudieron llegarle a través de diversos medios gracias a las músicas urbanas.

\section{BIBLIOGRAFÍA}

Carpentier, A. (1987). Ese músico que llevo dentro. Madrid: Siglo XXI.

Chemberdjí, V. (2010). Lina Prokófiev: una española en el gulag. Madrid: Siglo XXI de España.

Duthel, H. (2015). El caudillo - Francisco Franco y bahamonde: ¡Viva españa única! ¡Viva españa grande! ;Viva españa libre! Berlín: BoD- Books on Demand.

Fay, L.E. (2005). Shostakovich: A Life. Oxford: Oxford University Press.

Franco, E. (1977). "Prokofiev y España”, El País?.

Hess, C. A. (2004). Sacred Passion: The Life and Music of Manuel de Falla. Oxford: Oxford University Press.

Heyer, M. (2014). "Dmitri Shostakovich (Work list)", Sikorski?.

Hulme, D.C. (2010). Dmitri Shostakovich Catalogue: The First Hundred Years and Beyond. Scarecrow Press: London.

Kowalsky, D. (2004). La Unión Soviética y la Guerra Civil española: una revisión crítica. Madrid: Grupo Planeta.

\footnotetext{
${ }^{7}$ Disponible en: https://elpais.com/diario/1977/04/17/cultura/230076005 850215.html [Última consulta: 13 de marzo de 2017].

${ }^{8}$ Disponible en:

http://www.sikorski.de/media/files/1/12/1014/1085/8958/schostakowitsch werkverzeichnis.pdf. [Última consulta: 14 de marzo de 2017].
}

Cuadernos de Investigación Musical, 2017, diciembre, $\mathrm{n}^{\circ}$ 3, págs. 20-49.

ISSN: $2530-6847$ 


\section{REFERENCIAS HISPANAS EN OBRAS DE SHOSTAKOVICH DE LA DÉCADA \\ DE LOS AÑOS 50}

Lee, G. C. (2013). Listening to Stanley Kubrick: The Music in his Films. Toronto: Rowman and Littlefield.

Li, L. (2016). Memory, Fluid Identity, and the Politics of Remembering: The Representations of the Chinese Cultural Revolution in English-speaking Countries. Leiden: Brill.

Locke, R.P. (2015). Music and the Exotic from the Renaissance to Mozart. Cambridge: Cambridge University Press.

Meyer, K. (1997). Shostakovich, su vida, su obra, su época. Madrid: Alianza Música.

Riley, J. (2004). Dmitri Shostakovich: A Life in Film: The Filmmaker's Companion. London: I.B Tauris.

Sánchez Rodríguez, V. (2015). "Proyecciones cinematográficas de la enseñanza musical durante el franquismo". En: Montoya Rubio, J. C. (ed.). Didáctica a través de la canción popular y los medios andiovisuales. Nuevas perspectivas pedagógicas para la educación musical, pp: 319-350. Salamanca: Amarú.

Zamudio, D. (2001). "El folklore musical en Colombia”. En: Bermúdez, E. Cortés, J. (ed.). Musicología en Colombia: una introducción, pp: 129-156. Bogotá: Universidad Nacional de Colombia. Fac. de Artes. Programa de Maestría Historia y Teoría del Arte y la Arquitectura.

Fecha de recepción: 21/10/2017

Fecha de aceptación: 23/11/2017 